\title{
Extreme complications related to bevacizumab use in the treatment of ovarian cancer: a case series from a III level referral centre and review of the literature
}

\author{
Luigi Carlo Turco $^{1,2 \#}$, Gabriella Ferrandina ${ }^{3,4 \#}$, Virginia Vargiu ${ }^{3}$, Serena Cappuccio ${ }^{3}$, Anna Fagotti ${ }^{3,4}$, \\ Giuseppina Sallustio, $^{4,5}$, Giovanni Scambia ${ }^{3,4}$, Francesco Cosentino ${ }^{2}$ \\ ${ }^{1}$ Mater Olbia Hospital, Gynaecology and Breast Unit, Olbia; ${ }^{2}$ Division of Gynecologic Oncology, Gemelli-Molise, Università Cattolica del Sacro \\ Cuore, Campobasso, Italia; ${ }^{3}$ Department of Woman's, Children's and Public Health, Fondazione Policlinico Universitario A. Gemelli IRCCS, Roma, \\ Italia; ${ }^{4}$ Università Cattolica del Sacro Cuore, Roma, Italia; ${ }^{5}$ Department of Radiology and Diagnostic Imaging, Gemelli-Molise, Università Cattolica \\ del Sacro Cuore, Campobasso, Italia \\ Contributions: (I) Conception and design: LC Turco, G Ferrandina, F Cosentino; (II) Administrative support: G Scambia, A Fagotti; (III) Provision of \\ study materials or patients: F Cosentino, G Scambia, G Sallustio, V Vargiu, LC Turco, S Cappuccio; (IV) Collection and assembly of data: LC Turco, \\ V Vargiu, S Cappuccio; (V) Data analysis and interpretation: LC Turco, G Ferrandina, V Vargiu, S Cappuccio; (VI) Manuscript writing: All authors; \\ (VII) Final approval of manuscript: All authors.
}

\#These authors contributed equally to this work.

Correspondence to: Serena Cappuccio, MD. Fondazione Policlinico Universitario A. Gemelli IRCCS - Department of Women's and Children's Health, Roma, Italia. Email: sxcappuccio@gmail.com.

\begin{abstract}
In patients undergoing debulking surgery for ovarian cancer (OC), bevacizumab-combined chemotherapy has been reported to be associated with an increased incidence of adverse events (AEs). Reports in the literature have noted the overall morbidity of bevacizumab to be between $3.7 \%$ and $9 \%$. The aim of this study is to report uncommon and unusual manifestations of morbidity in surgical cases performed at our third level referral centers for gynecologic oncology. Additionally, we review the rare and severe bevacizumab-related complications that have been described in the literature. We defined as "extreme", the particularly rare and/or severe complications up to determining a life-threatening condition or death, which are related to the use of bevacizumab. A case-series of extreme complications registered at our institutions were reported. In addition, a literature search of the PubMed, MEDLINE and EMBASE electronic databases was performed for this review. The studies collected included: 8 randomized controlled trials (RCT) and 5 prospective observational, 1 prospective phase-IV, 10 prospective phase-II, 2 prospective phase-I, and 20 retrospective studies, as well as 9 case reports. Bevacizumab was administered as primary treatment in adjuvant and neo-adjuvant setting in 16 and 5 studies respectively, as treatment for recurrence in 36 trials, and for secondary cytoreductive surgery (SCS) in 3 studies. The overall population administered with bevacizumab numbered 7,096 women. Extreme complications were observed in 591 patients, with a morbidity rate of the $8.3 \%$. Overall, central nervous system (CNS), cardiovascular, gastrointestinal (GI) and primary infectious complications were seen in 22 patients $(0.3 \%), 261$ patients $(3.7 \%), 159$ patients $(2.2 \%)$, and 8 patients $(0.13 \%)$, respectively. Hemorrhagic and wound complications occurred in 18 women $(0.25 \%)$, and 112 women (1.6\%), respectively. Extreme complications related to the use of bevacizumab are rare, and often go unrecognized. The recognition and immediate management of such rare and life-threatening complications in patients treated at third level referral centers could significantly improve patient survival.
\end{abstract}

Keywords: Bevacizumab; ovarian cancer (OC); complications; translational medicine/personalized medicine; case series

Submitted Jun 03, 2020. Accepted for publication Oct 30, 2020.

doi: $10.21037 /$ atm-20-4448

View this article at: http://dx.doi.org/10.21037/atm-20-4448 


\section{Introduction}

Bevacizumab is a well-known antiangiogenic drug whose use has been proven to be effective for patients with ovarian cancers (OC) (1). Despite its efficacy, bevacizumab-combined chemotherapy was firstly associated to an increased incidence of adverse events (AEs) during treatment or surgical complications in those patients undergoing debulking surgery $(2,3)$. Subsequent literature regarding the relationship between surgery and bevacizumab-combined chemotherapy did not confirm this data (4). In fact, the antiangiogenic drug was shown to have an acceptable toxicity profile when administered with adjuvant (ACT), or neoadjuvant (NACT) chemotherapy, in the treatment of advanced ovarian cancer (AOC). In women with recurrent ovarian cancers who either did, or did not undergo secondary cytoreductive surgery (SCS), the use of bevacizumab, overall, was well tolerated (4-17), so that historically in 2016, FDA approved bevacizumab for the treatment of platinum-sensitive recurrent epithelial ovarian cancer in combination with platinum-based chemotherapy (18).

Several studies, as well as a recent review of the literature have estimated that the overall surgical morbidity of bevacizumab ranges between $3.7 \%$ and $9 \%(4,8,10,19)$. In particular, gastrointestinal (GI) complications, infectious toxicity and wound healing alterations were estimated to be around $7 \%, 9 \%$ and $7 \%$, respectively $(8,10,19)$.

In addition to surgical complications, other forms of toxicity have been noted to occur in different systems, such as central nervous or cardiovascular ones, occasionally manifesting as rare and life-threatening syndromes $(1,2)$.

The aim of this study is to present a collection of cases with surgical morbidity eliciting peculiar and anecdotal manifestations that were observed at our third level referral centers for gynecologic oncology. In addition, rare and severe bevacizumab-related complications previously reported in the literature are here reviewed.

The knowledge of the rarer forms of bevacizumab toxicity may be useful to better evaluate the possible future combinations of this antiangiogenic drug with the most recent biological therapies such as PARP inhibitors, which appear to have a synergistic effect in inducing hypoxic damage and necrosis of cancer cells. For these combinations, there are currently several trials ongoing (20).

We present the following article in accordance with the AME CASE SERIES reporting checklist (available at http://dx.doi.org/10.21037/atm-20-4448).

\section{Methods}

This study was conducted in accordance with the Declaration of Helsinki (as revised in 2013) and study it was reviewed and approved by the intramural Integrated Research Ethics Board (approval number DIPUSVSP-26-05-2081). Written informed consent was obtained from the patient for publication of this study and any accompanying images.

We defined as "extreme", uncommon, rare and/or severe complications up to determining a life-threatening condition or death of the patient, which are directly or indirectly attributable to the use of bevacizumab in the treatment of OC. Extreme complications are primarily associated with AEs of grade 4 or 5 (21).

AEs are defined as "uncommon" when their frequencies range between $1 / 1,000$ and $1 / 100$, and as "rare" and "very rare" when their frequencies are between $1 / 10,000$ and $1 / 1,000$, and $<1 / 10,000$, respectively (22).

Hematological AEs and common chemotherapy toxicities (e.g., nausea, vomiting, constipation, fatigue, altered enzymes, etc.) were not included in this study. In addition, non-English language reports, those based on in vitro and animal experimentation, and literature reviews were excluded.

Our Institution's reported cases have been presented anonymously with the informed consent of the patients involved. Data were retrieved from medical records. If a case was already presented in other forms and for other purposes in literature, a note of reference was placed at the end of the report.

This systematic review was conducted in accordance with PRISMA guidelines (23).

A literature search of the PubMed, MEDLINE and EMBASE electronic databases was performed using the following terms: "bevacizumab" AND "ovarian cancer" AND “complications" OR “toxicity” OR "adverse events".

Three authors (LCT, SC and VV) independently reviewed and classified all abstracts. Agreement about potential relevance was reached by consensus of the researchers. The same three authors obtained full-text copies of papers, and separately extracted relevant data regarding study toxicities. Later, the three reviewers discussed all inconsistencies and, if needed, a fourth author (GF) made a decision.

If more than one study was published on the same cohort population, the one with the most comprehensive information was utilized. All types of articles reporting cases with such characteristic defined as "extreme" were 
included in the present literature review. If a study reported AEs without indicating their severity, or, if in the same case, they were not associated with a patient's death (G5 de facto), the paper was not taken under consideration for the review. If a study reported the undefined classification $\geq 3$ of AEs, however, it was taken into consideration for this review and the AEs evaluated on a case by case basis for rarity and severity.

After study selection, the relevant data were collected and analyzed, and the results were reported using a narrative approach.

We also distinguished AEs as "uncommon/rare" (U/R), "U/R and life-threatening" (U/R-LT) or simply "lifethreatening" (LT) when severe but more common, and as "fatal" (FAE) $(22,23)$.

The "mortality-rate" was defined as the percentage of the death-per-complication compared with the total population experiencing the same complication.

Follow up of patients in the case series is updated periodically according to our hospital oncologic guidelines.

\section{Results}

\section{Case series}

The following cases are from the experience of the Gynecologic Oncology units of the third level referral centers Fondazione Policlinico Universiario A. Gemelli IRCCS (FPG) and Gemelli-Molise (GM). Local IRB approval was obtained (prot. aprov. DIPUSVSP-26-05-2081) Cases are tabulated in Table 1.

\section{Case 1: a case of gastric perforations}

$\mathrm{PC}$ is a 66-year-old woman who received the diagnosis of suspected OC at GM. In February 2019, she underwent PDS with radical hysterectomy, bilateral salpingooophorectomy, sigmoidectomy, omentectomy, bilateral diaphragmatic peritonectomy, splenectomy, and appendectomy. No gross tumor remained at the conclusion of surgery. Pathology review demonstrated a highgrade serous ovarian cancer, stage IIIC. There were no perioperative complications during hospitalization. The patient received ACT with Carboplatin and Paclitaxel in May, 2019. Bevacizumab was administered from the second cycle. After the fourth course of ACT, the patient presented with fever, abdominal pain and signs of bowel obstruction. A CT-scan showed signs of gastric perforation (Figure $1 A, B$ ) and an urgent exploratory laparotomy was performed. Abundant bilious-enteric collections were found in the abdominal cavity. The site of perforation was suspected to be the posterior gastric wall, but it could not be reached surgically because of the presence of the frozen abdomen syndrome. Gastro-duodenoscopy was performed intraoperatively and the perforation of the posterior gastric wall was confirmed. Nasogastric and intraperitoneal perigastric drains were placed but no further invasive procedures were performed due to the patient's severe clinical condition and the high risk of further complications. The postoperative course was complicated by a wound infection and respiratory insufficiency necessitating a tracheostomy. Vacuum Assisted Closure (VAC) was employed, and total parenteral nutrition was initiated. A second CT-scan employing oral Gastrografin ${ }^{\circledR}$ was performed revealing persistence of the perforation. The patient was transferred to FPG for further treatment. After a multidisciplinary evaluation, a second surgery was deemed to be contraindicated and invasive endoscopic treatment was proposed. Under general anesthesia an upper endoscopy revealed two adjacent perforations at the level of the fundus that were sutured with endoscopic instruments. No complications occurred during the procedure. The patient began oral intake on the third postoperative day without any complications. The tracheostomy was removed and the patient was discharged. The patient remains in good clinical condition; however, ACT was discontinued (24).

\section{Case 2: a case of bowel perforations, rare abscess formation and cellulitis}

$\mathrm{NO}$ is a 52 -year-old woman that was admitted to GM because of fever and a recurring sub-occlusive/occlusive condition. In March, 2019, she was diagnosed with advanced serous high-grade ovarian cancer, IIIA FIGO stage, for which she first underwent PDS in another hospital. There, a total hysterectomy, bilateral salpingo-oophorectomy, pelvic peritonectomy, radical omentectomy, appendectomy, pelvic and lumbo-aortic lymphadenectomy, as well as a resection of a cecal nodule of carcinoma were performed. The patient was treated with ACT based on carboplatin and taxol including bevacizumab in the same hospital.

In June, 2019, between the second and the third courses of chemotherapy, the patient presented with abdominal pain, a sub-occlusive status and a fever that solved spontaneously after two days. She was administered the third cycle of chemotherapy with bevacizumab following a one-week delay. Ten days following the third administration of chemotherapy, the patient presented with a new-onset 
Table 1 Review of the literature reporting all the studies with extreme complications associated to bevacizumab administration

\begin{tabular}{|c|c|c|c|c|c|c|c|c|c|c|c|c|c|c|c|}
\hline Cases & Age & $\begin{array}{l}\text { FIGO stage, } \\
\text { histology }\end{array}$ & $\begin{array}{l}\text { Biologic features and } \\
\text { disease presentation }\end{array}$ & $1^{\text {st }}$ diagnosis date 7 & Treatment, CT type & $\begin{array}{l}1^{\text {st }} \text { Recurrence } \\
\text { date, PFI }\end{array}$ & $\begin{array}{l}1^{\text {st }} \text { Recurrence } \\
\text { treatment, CT type }\end{array}$ & $\begin{array}{l}2^{\text {nd }} \text { Recurrence } \\
\text { date }\end{array}$ & $\begin{array}{l}2^{\text {nd }} \text { Recurrence } \\
\text { treatment, CT type }\end{array}$ & Complication date & $\begin{array}{l}\text { Time from last } \\
\text { bevacizumab (days/ } \\
\text { note) }\end{array}$ & $\begin{array}{l}\text { Complication type, } \\
\text { Grade (CTCAE v3.0) }\end{array}$ & $\begin{array}{l}\text { Complication } \\
\text { treatment }\end{array}$ & TTC (days/note) & $\begin{array}{l}\text { DOD (yes/ } \\
\text { no), OS } \\
\text { (mo) }\end{array}$ \\
\hline $\begin{array}{l}\text { Case \#1 } \\
\text { PG }\end{array}$ & & IIIC & $\begin{array}{l}\text { Histology HGSOC; Ca } \\
125 \text { secretor; Ascites no; } \\
\text { BRCA wild type }\end{array}$ & February 2019 & $\begin{array}{l}\text { PDS + ACT; carbo- } \\
\text { taxol ( } 4 \text { courses) } \\
+ \text { bevacizumab ( } 3 \\
\text { administration from } \\
\text { the II course of CT) }\end{array}$ & - & - & - & - & $\begin{array}{l}\text { July 2019; during } \\
\text { ACT }\end{array}$ & $\begin{array}{l}7 \text { (after the } 3^{\text {rd }} \\
\text { administration of } \\
\text { bevacizumab) }\end{array}$ & Gastric perforation, IV & $\begin{array}{l}\text { Exploratory LPT } \\
\text { with drainage } \\
\text { positioning; } \\
\text { endoscopic gastric } \\
\text { suture }\end{array}$ & Suspended & No, 14 \\
\hline $\begin{array}{l}\text { Case \#2 } \\
\text { NO }\end{array}$ & & IIIA & $\begin{array}{l}\text { Histology HGSOC; Ca } \\
125 \text { secretor; Ascites no; } \\
\text { BRCA wild type }\end{array}$ & March 2019 & $\begin{array}{l}\text { PDS + ACT; carbo- } \\
\text { taxol + bevacizumab } \\
\text { ( } 3 \text { courses in total) }\end{array}$ & - & - & - & - & $\begin{array}{l}\text { June 2019; during } \\
\text { ACT }\end{array}$ & $\begin{array}{l}10 \text { after the } 3^{\text {rd }} \\
\text { administration of } \\
\text { bevacizumab) }\end{array}$ & $\begin{array}{l}\text { Voluminous pelvic } \\
\text { abscess (fecal } \\
\text { collection), IV; } \\
\text { extrafascial abscess } \\
\text { (from right iliac fossa to } \\
\text { the right groin), IV }\end{array}$ & $\begin{array}{l}\text { Exploratory LPT } \\
\text { + ileum-caecal } \\
\text { resection; surgical } \\
\text { drainage + VAC } \\
\text { therapy }\end{array}$ & Suspended & No, 13 \\
\hline $\begin{array}{l}\text { Case \#3 } \\
\mathrm{TM}\end{array}$ & & IIB & $\begin{array}{l}\text { Histology poorly } \\
\text { differentiated } \\
\text { adenocarcinoma of the } \\
\text { ovary; Ca } 125 \text { secretor; } \\
\text { Ascites no; BRCA wild } \\
\text { type }\end{array}$ & December 2011 & $\begin{array}{l}\text { PDS + ACT; carbo- } \\
\text { taxol (6 courses) }\end{array}$ & $\begin{array}{l}\text { March 2017; } 58 \\
\text { mo }\end{array}$ & $\begin{array}{l}\text { SCS+reCT; Carbo- } \\
\text { gem }(6 \text { courses) + } \\
\text { bevacizumab (22 } \\
\text { administrations in total) }\end{array}$ & December 2018 & $\begin{array}{l}3^{3^{d \mathrm{~d}} \text { Tertiary }} \\
\text { cytoreductive } \\
\text { surgery }\end{array}$ & $\begin{array}{l}\text { January 2019; after } \\
\text { tertiary cytoreductive } \\
\text { surgery }\end{array}$ & 150 & $\begin{array}{l}\text { Bowel perforation, } \\
\text { IV; ureteral fistula } \\
\text { (uroperitoneum), IV; } \\
\text { complete wound's } \\
\text { dehiscence, IV; floating } \\
\text { thrombus in the LV } \\
\text { (left ventricle) and Tako } \\
\text { Tsubo syndrome, IV }\end{array}$ & $\begin{array}{l}\text { Exploratory LPT } \\
\text { + perforation } \\
\text { suturing and } \\
\text { ileostomy; ureteral } \\
\text { resection and re- } \\
\text { implantation; VAC } \\
\text { therapy; LWMH }\end{array}$ & 150 & No, 88 \\
\hline $\begin{array}{l}\text { Case \#4 } \\
\text { CMT }\end{array}$ & & IVB & $\begin{array}{l}\text { Histology HGSOC; Ca } \\
125 \text { secretor; Ascites yes; } \\
\text { BRCA n.a. }\end{array}$ & July 2016 & $\begin{array}{l}\text { PDS + ACT; carbo- } \\
\text { taxol ( } 4 \text { courses) } \\
+ \text { bevacizumab ( } 1 \\
\text { administration from } \\
\text { the IV course of CT) }\end{array}$ & - & - & - & - & $\begin{array}{l}\text { January 2017; during } \\
\text { ACT }\end{array}$ & $\begin{array}{l}24 \text { (after the } 1^{\text {th }} \\
\text { bevacizumab } \\
\text { administration) }\end{array}$ & $\begin{array}{l}\text { Colonic-ureteric fistula, } \\
\text { III/IV }\end{array}$ & $\begin{array}{l}\text { Ureteral resection } \\
\text { and re-implantation } \\
\text { + ileostomy }\end{array}$ & 45 & No, 45 \\
\hline $\begin{array}{l}\text { Case \#5 } \\
\text { AM }\end{array}$ & & IIIC & $\begin{array}{l}\text { Histology HGSOC; Ca } \\
\text { 125; Secretor; Ascites; } \\
\text { yes; BRCA; mutated }\end{array}$ & September 2013 & $\begin{array}{l}\text { PDS + ACT; carbo- } \\
\text { taxol }(6 \text { courses) + } \\
\text { bevacizumab ( } 21 \\
\text { administration in total } \\
\text { from the II course of } \\
\text { CT) }\end{array}$ & $\begin{array}{l}\text { December 2017; } \\
46 \text { mo }\end{array}$ & sCs & - & - & $\begin{array}{l}\text { March 2018; after } \\
\text { scS }\end{array}$ & $>1,000$ & $\begin{array}{l}\text { Arterial-colic fistula } \\
\text { (external iliac artery- } \\
\text { descending colon), IV }\end{array}$ & $\begin{array}{l}\text { Total colectomy and } 4 \\
\text { left iliac-femoral } \\
\text { bypass (saphenous } \\
\text { graft) }\end{array}$ & & Yes, 66 \\
\hline
\end{tabular}



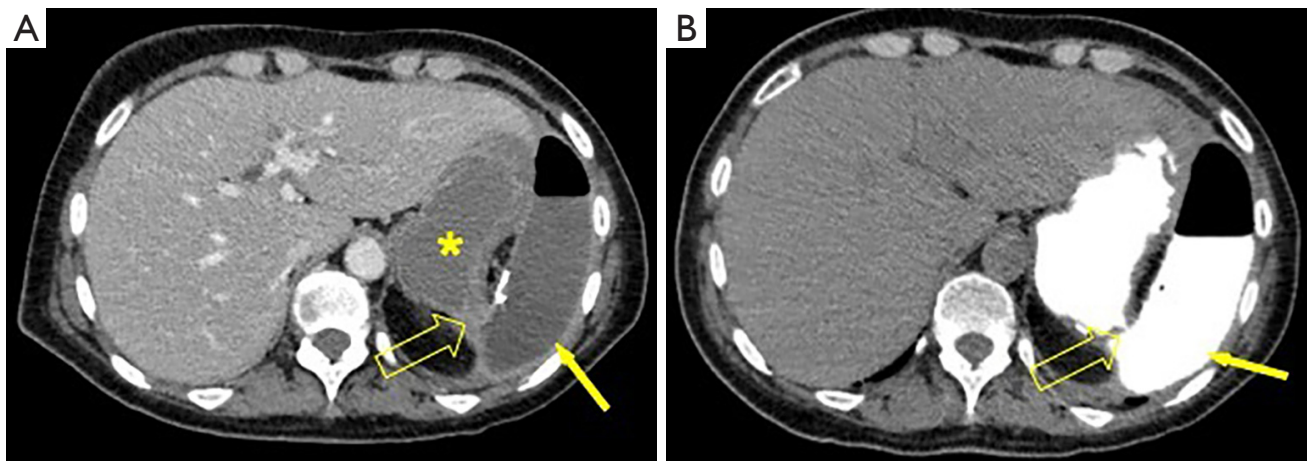

Figure 1 CT-scan imaging revealing the gastric perforation and abdominal spreading of contrast medium in case \#1. (A) Sub-phrenic collection (filled arrow) with hydro-aerial level and focal attraction of the gastric wall (empty arrow). (B) Opacification of the collection after oral administration of Gastrografin ${ }^{\circledR}$ (filled arrow) and visualization of a thin through between gastric wall and collection (empty arrow) (24). *, stomach.
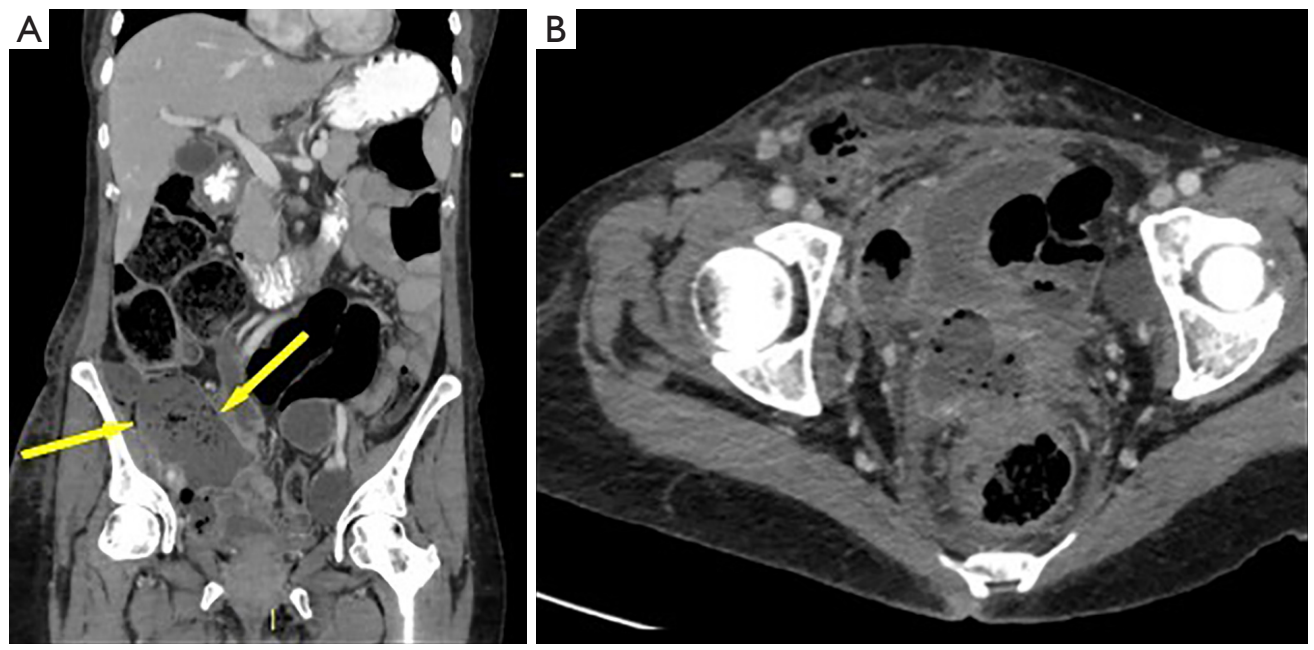

Figure 2 CT-scan imaging revealing the abdominal fecal collection trough the right inguinal canal in case \#2. (A) Mixed collection of air bubbles in peri-colonic area (filled arrows). (B) Extension of the mixed collection in the right pelvic fossa medial to the external iliac vessels (arrow head) and in the inguinal canal (empty arrow).

sub-occlusion, high fever and malaise. An abdominal CTscan revealed the presence of two voluminous lymphoceles of 6 and $10 \mathrm{~cm}$, respectively, as well as conglomerate tenual loops and a 6-cm distension of the colon. Pyelectasis of the right kidney was also noted. The patient was then admitted to our GM unit for evaluation. A subsequent CT scan revealed abdominal fecal collections. The right pelvic collection was seen to be compressing the right ureter, extending into the obturator canal and crossing into the inguinal canal (Figure $2 A, B$ ). An exploratory laparotomy was performed. Marked colonic distention and a voluminous pelvic collection of fecal material that had extended into the right obturator fossa were observed. The collection was caused by a covered spontaneous perforation of the caecum. Friable and macerated small bowel loops adjacent to the collection were present. An ileo-caecal resection with mechanical ileo-colic anastomosis was undertaken. The right ureter was encased in fibrotic tissue, causing a tight stenosis and a hydroureter. After a difficult and careful ureterolysis, a ureteral stent was placed by cystoscopy. The abdominal cavity, including the obturator fossa and proximal inguinal canal were thoroughly irrigated and explored. Subsequently, an ileostomy was performed.

Nine days following surgery, the patient developed a right groin mass. A large edematous area with cellulitis features that extended from the right iliac fossa up to the large lips of the 

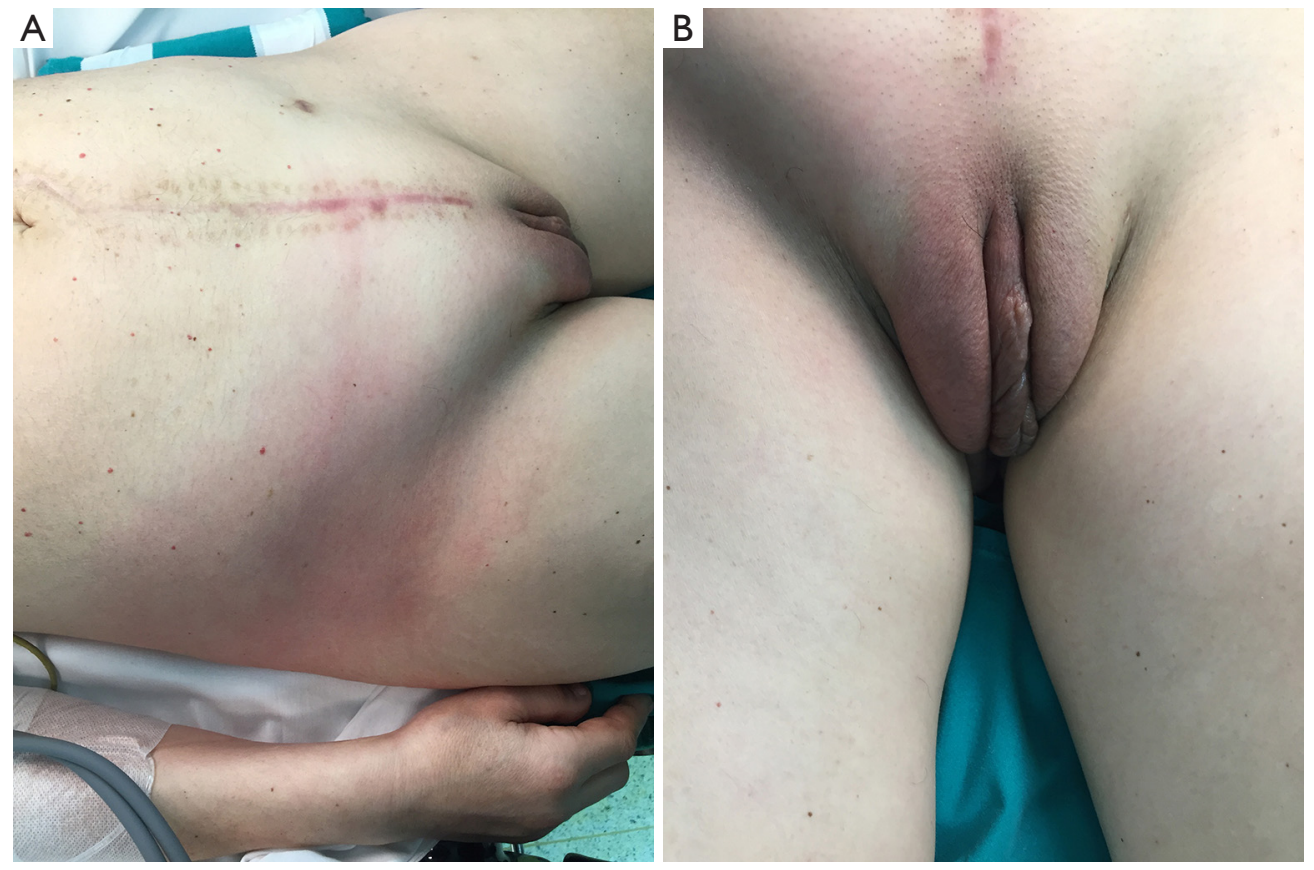

Figure 3 Cellulitis in case \#2. (A) Right groin swelling (abscess). (B) Vulvar infiltration.
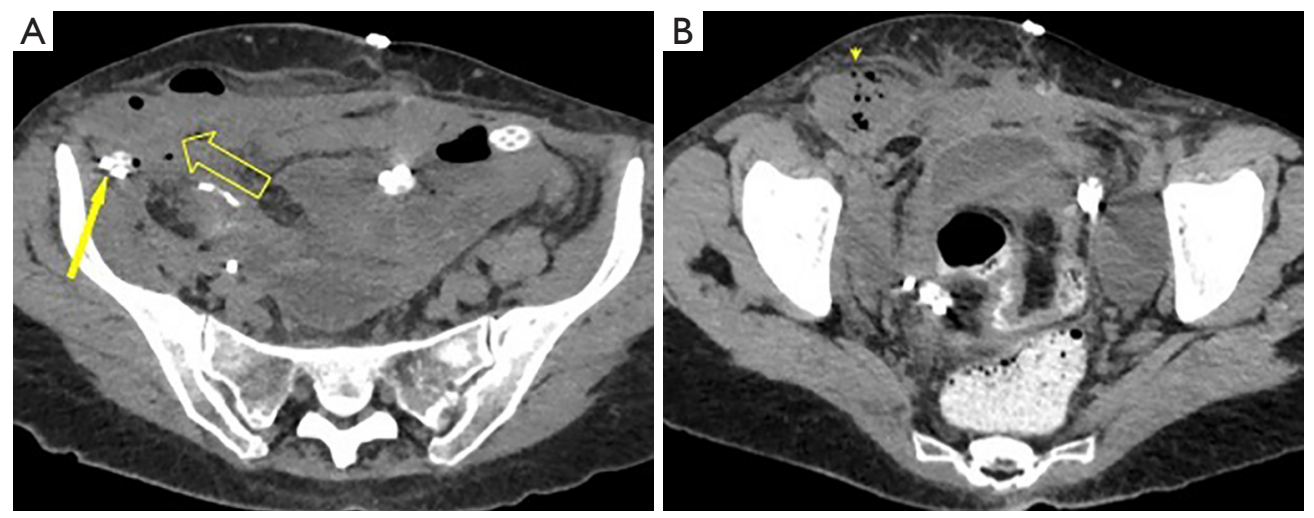

Figure 4 CT-scan imaging revealing the right abdominal-inguinal abscess and cellulitis in case \#2. (A) Right iliac fossa abscess (empty arrow), adjacent to the drainage tube (filled arrow) with involvement of the abdominal wall. (B) Protrusion of the abscess in the inguinal canal (arrow head).

vulva was noted (Figure $3 A, B$ ). CT-scan revealed a $10 \mathrm{~cm}$ extrafascial abscess at the level of the right iliac fossa with extension to the right groin though the inguinal canal (Figure $4 A, B$ ). An incision and drainage procedure was performed and the wound was allowed to close by secondary intention, utilizing a VAC. Broad-spectrum antibiotic were administered. During hospitalization, due to large intestinal resection, she also developed short bowel syndrome and a resulting malnutrition for which she was given parenteral nutrition.
She was discharged 18 days following the first surgery and underwent uncomplicated loop ileostomy closure one month later. Chemotherapy subsequently was suspended and, at follow-up, the patient remained disease free.

\section{Case 3: a case of concomitant bowel perforation,} ureteral fistula, wound dehiscence, cardiac ischemia and intra-cardiac thrombus

TM is a 71-year-old woman who was hospitalized in 

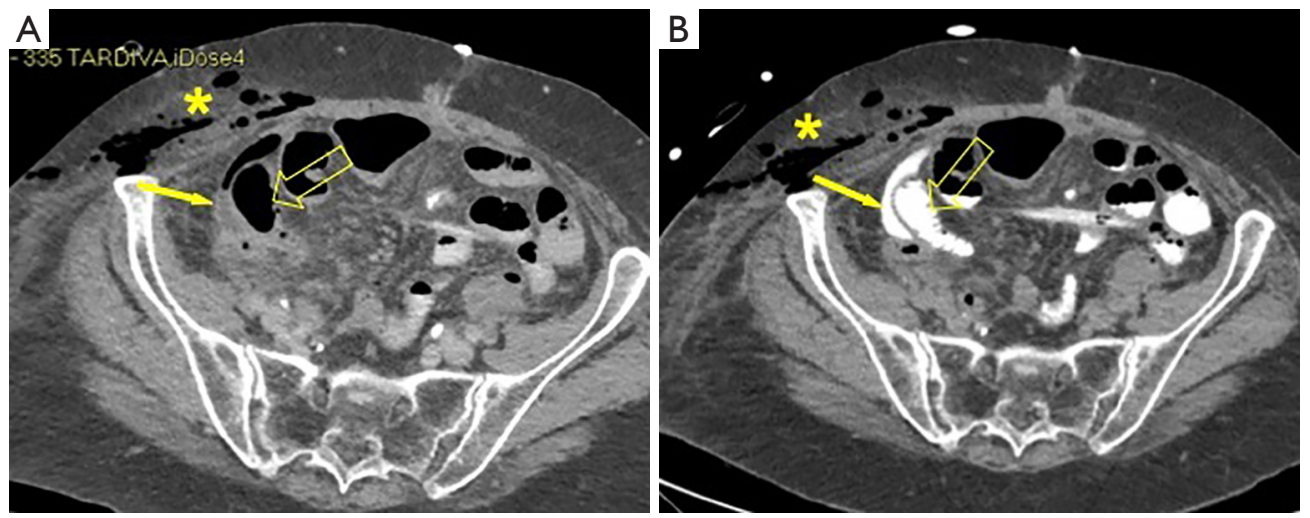

Figure 5 CT-scan imaging revealing the bowel perforation in case \#3. (A) Small collection (filled arrow) in the right iliac fossa surrounding a tenuous loop (empty arrow). (B) Passage of contrast medium administered orally in the later phase; cellulitis and emphysema of the subcutaneous tissues of the abdominal wall (asterisk).

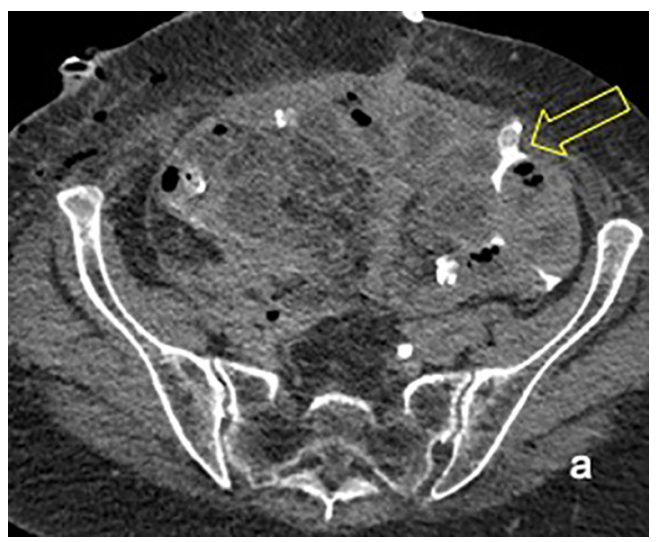

Figure 6 Uro-CT-scan imaging revealing the presence of ureteral fistula and uro-peritoneum in case \#3. Excretory phase: spilled urine iodized around the drainage tube (empty arrow).

January, 2019, at GM for a second platinum sensitive ROC. The patient had no comorbidities except for hypertension. OC was firstly diagnosed in December, 2011. Pathology revealed a poorly differentiated adenocarcinoma, FIGO stage IIB (2014 classification). The patient underwent PDS, achieving no residual tumor (no gross residual) at GM. Given the histology and FIGO stage, she was treated with 6 courses of carboplatin and paclitaxel. Oncologic followup remained negative until March, 2017, when a PET-CT scan revealed an increased uptake in the pelvis involving the bowel and left presacral space [platinum free interval (PFI) 58 months, progression free survival (PFS) 63 months].

She underwent SCS, including sigmoid-rectal segmental resection with termino-terminal anastomosis with mechanical suture, pelvic peritonectomy and appendectomy (no gross residual).

Pathology confirmed the presence of disease relapse, and 6 courses of reCT with carboplatin and gemcitabine plus bevacizumab were administered. A total of 22 cycles of bevacizumab were administered (last treatment in August, 2018).

A second pelvic relapse occurred in December, 2018. CT-scan at that time revealed the presence of a $2.5 \mathrm{~cm}$ segment of solid vascular tissue, located between the vaginal vault and the rectum. Also seen were smaller disease nodules (maximum size $2.1 \mathrm{~cm}$ ) in the pelvic fatty tissue, some of which were attached to tenual loops.

In January 2019, five months after the last bevacizumab administration, the patient underwent a tertiary cytoreductive surgery. After a difficult adhesion-lysis and retroperitoneal tissue dissection, the patient underwent a subtotal colpectomy and ileal resection with mechanical ileo-ileal anastomosis. Postoperatively, severe, LT complications occurred, including a spontaneous bowel perforation (Figure $5 A, B$ ). During an exploratory laparotomy, a perforation was discovered in the distal ileum not involving the area of prior anastomosis. The perforation was sutured, the abdomen irrigated and an ileostomy was created. Three days later, a pelvic drain revealed the presence of urine and a CT-scan confirmed the presence of a left ureteral fistula (Figure 6). A new laparotomy was performed and the ureter was resected, followed by the placement of a ureteral stent. A postoperative wound infection with wound dehiscence and consequent intestinal loops exposure requiring the placement of a VAC occurred. She was ultimately discharged 43 days after the first surgery. 
Page 8 of 25

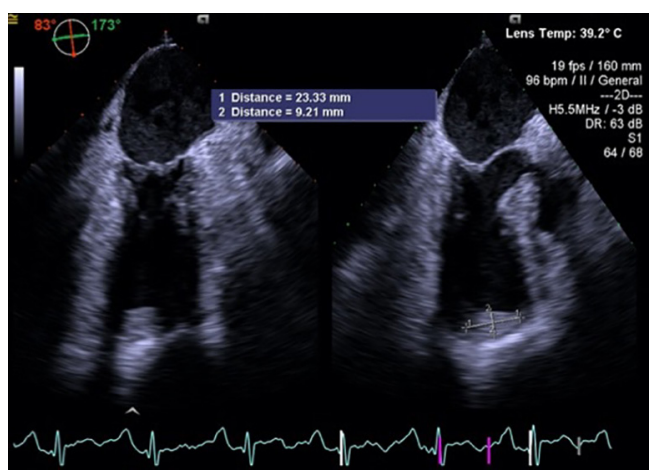

Figure 7 Cardiac ultrasound imaging of the Tako-Tsubo syndrome and thrombus in the right ventricle apex (filled arrow) in case \#3.

The patient was readmitted 2 weeks later with fever. A persistent ureteral leak was observed on a CT scan, and a nephrostomy tube was placed. A cardiology consultation was obtained because of malaise. Subsequent echocardiography and coronary angiography revealed Tako Tsubo syndrome (myocardial infarction due to coronary artery spasm without obstruction) and the presence of a left ventricular thrombus. Echocardiography revealed extensive ventricular apical akinesia with hypercontractility of the basal segments. The ejection fraction was $45 \%$ (Figure 7 ).

Low molecular weight heparin (LMWH) (100 IU/Kg twice daily), CardioASA, and a $\beta$-blocker were administered, and the patient was discharged after 30 days.

Five months following the first surgery a new peritoneal recurrence was seen and the patient received platinumbased second-line reCT. She remains alive with stable disease.

\section{Case 4: a case of rare arterial-enteric fistula}

$\mathrm{AM}$ is a 75 -year-old woman who was admitted to FPG in February, 2018, for ROC. She was diagnosed with AOC in September, 2013, and a PDS was performed. Diagnostic laparoscopy revealed diffuse carcinomatosis with omental caking. She underwent laparoscopic PDS through a retrograde radical hysterectomy with en-bloc recto-sigmoid resection, bilateral salpingo-oophorectomy, radical omentectomy, total splenectomy with en-bloc distal pancreatectomy, bilateral diaphragmatic peritonectomy, removal of the peritoneum of the parieto-colic gutters, appendectomy and an end-to-end colorectal mechanical anastomosis with creation of a temporary loop ileostomy.

Pathology revealed high-grade, serous ovarian carcinoma (IIIC FIGO stage) in all surgical specimens. She was treated with 6 courses of carboplatin and paclitaxel associated to bevacizumab between October, 2013, and February, 2014, followed by 16 courses of bevacizumab until February, 2015.

Oncologic follow-up remained negative until December, 2017, when a PET-CT scan showed the presence of recurrent disease in the left para-anastomotic pelvic tissue and in the left obturator lymph nodes.

In February, 2018, the patient underwent laparoscopic SCS with left pelvic lymphadenectomy. Pathology revealed metastasis. She was discharged 5 days following surgery. The patient did well until 22 days after surgery, when she was admitted with a massive rectal hemorrhage. Evaluation subsequently revealed a colonic wall lesion located $18 \mathrm{~cm}$ above the anal orifice as the source of massive bleeding. An arterial-colic fistula was found during an emergency laparotomy involving the left iliac artery. A total colectomy, preserving the pre-existing ileostomy loop, and a left iliacfemoral bypass with saphenous graft were performed. She was discharged in stable condition following a prolonged hospitalization. She was subsequently subjected to secondline chemotherapy but died of disease in March, 2019 (25).

\section{Case 5: a case of rare colonic-ureteric fistula}

CMT is a 45 -year-old woman who was diagnosed with ascites, pelvic masses, carcinomatosis and lymphadenopathy in July, 2016. A pelvic ultrasound confirmed the presence of ascites and adnexal and peritoneal nodules. She underwent an exploratory laparoscopy at GM, with evacuation of $5,000 \mathrm{~mL}$ of ascites. Of note, were a 6-cm pelvic mass, and nodules on the right hemi-diaphragm, abdominal wall and in the liver. An extensive resection, including bilateral salpingo-oophorectomy, hysterectomy, sigmoid segmental resection with colorectal anastomosis, peritonectomy of the right hemi-diaphragm, resection of the liver metastasis, splenectomy, and omentectomy were performed. The immediate postoperative course was uncomplicated, and she was discharged 10 days after surgery. Histology of the surgical specimens revealed high grade serous ovarian cancer (IVB FIGO stage). In the post-operative follow-up period the patient sustained a pulmonary embolism and she was anticoagulated. Ascites was noted at the time of CT scanning and a transabdominal drainage tube was placed. Six days later, a course of carboplatin and taxol was initiated. The transabdominal drainage tube was removed between the first and the second courses of ACT. Bevacizumab was subsequently added to the regimen. Following the fourth cycle of chemotherapy, the patient was admitted with a 


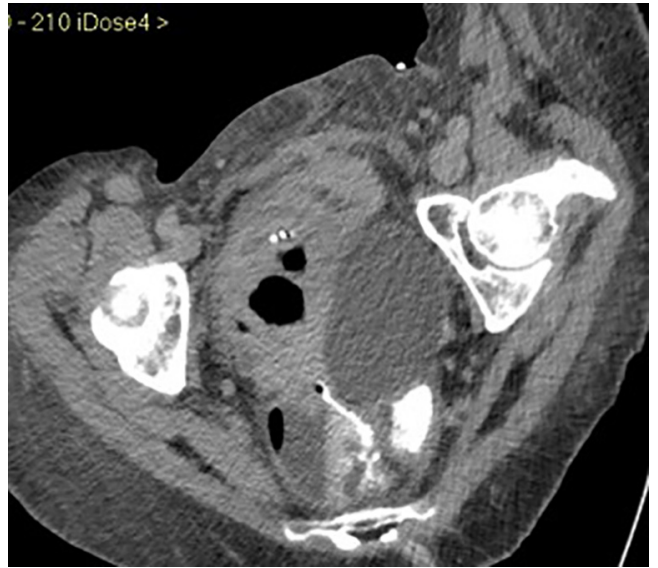

Figure 8 CT-scan imaging revealing the colonic-ureteric fistula in case \#5. Extensive communication of the right pelvic ureter (arrow) with the rectum (empty arrow), iodized urine in the left perirectal collection and in the rectum; lymphocele is indicated with an asterisk.

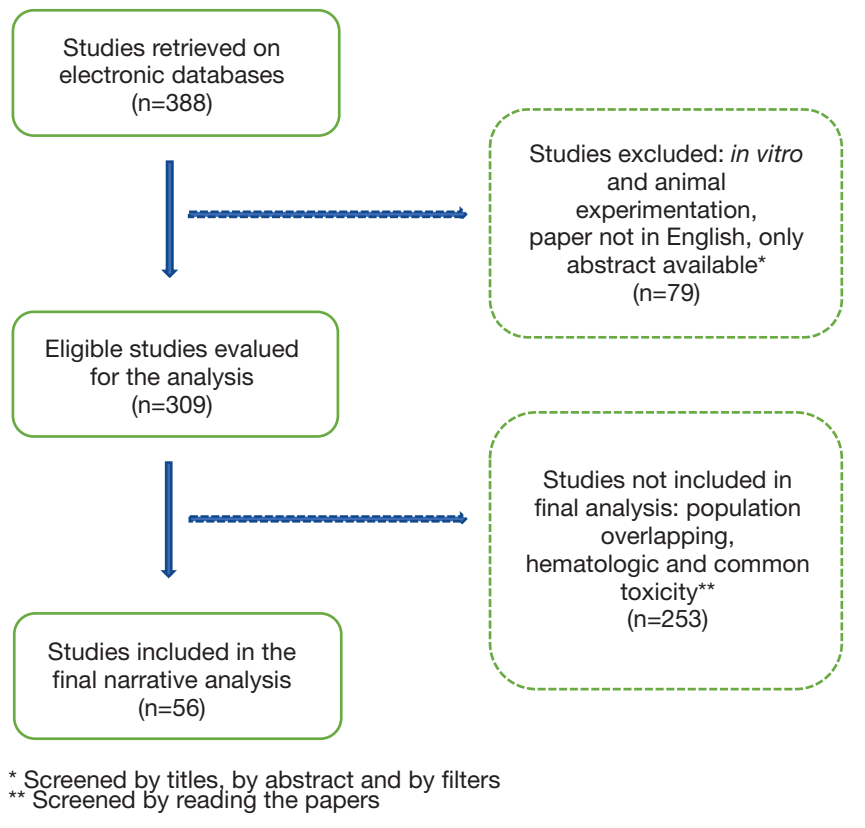

Figure 9 Studies identified screened and finally included in the systematic review.

bowel obstruction. A CT-scan revealed a fluid-filled cyst in the left pelvis with compression of the bladder, and air in the renal pelvis and then a recto-ureteral fistula (Figure 8). A laparotomy with a right ureteral segmental resection, stenting and an end-to-end anastomosis and an ileostomy were performed. The postoperative course was complicated by a mild surgical site infection, and she was discharged on the $20^{\text {th }}$ post-operative day. Subsequently, a fifth course of chemotherapy without bevacizumab (due to reported toxicity) was administered. In total, the patient completed six cycles of ACT. At the first follow-up visit, no evidence of disease was noted. The ureteral stent and ileostomy subsequently were removed, and the patient remains disease-free.

\section{Review of the literature}

As seen in Figure 9, 388 studies were retrieved from the electronic databases, with 188 (48.5\%) being excluded because they did not meet study inclusion criteria. Of the remaining 200 manuscripts, 144 (37\%) did not report data regarding extreme complications related to the use of bevacizumab. Therefore, only 56 studies (14.5\%) were included in the final analysis.

The studies collected included 8 randomized controlled trials (RCT), as well as 5 prospective observational, 1 prospective phase-I, 10 prospective phase-II, 2 prospective phase-I, and 20 retrospective studies. There were also 9 case reports.

Bevacizumab was administered as primary treatment in OC with ACT and NACT in 16 and 5 studies, respectively, and as salvage chemotherapy for recurrence (ReCT) in 36 trials. Three studies reported SCS concomitantly with bevacizumab administration. The total number of women that received bevacizumab was 7,096.

Table 2 demonstrates the U/R and/or severe complications reported in all the studies included in the present review.

Overall, the number of extreme complications observed was 591 , with a morbidity rate of the $8.3 \%$.

Table 3 shows the variety of AEs by system, classified according to rarity and severity.

Overall, central nervous system (CNS) complications were $22(0.3 \%)$, representing $3.7 \%$ of global morbidity. Of the CNS morbidity, there were 5 cases $(0.07 \%)$ of intracranial hemorrhage, 12 cases $(0.2 \%)$ of posterior leukoencephalopathy syndrome (PLES), 4 cases $(0.05 \%)$ of ischemia, and 1 case $(0.01 \%)$ of intracranial hypertension associated with seizures, representing $23 \%, 54.5 \%, 18 \%$, and $4.5 \%$, respectively. One case of intracranial hemorrhage was due to a rare spontaneous arterial dissection with consequent bleeding.

Cardiovascular system (CVS) complications numbered 261 (3.7\%), representing $44 \%$ of the global morbidity. 
Table 2 Complications presented for Class of rarity and severity scheduled for System affected

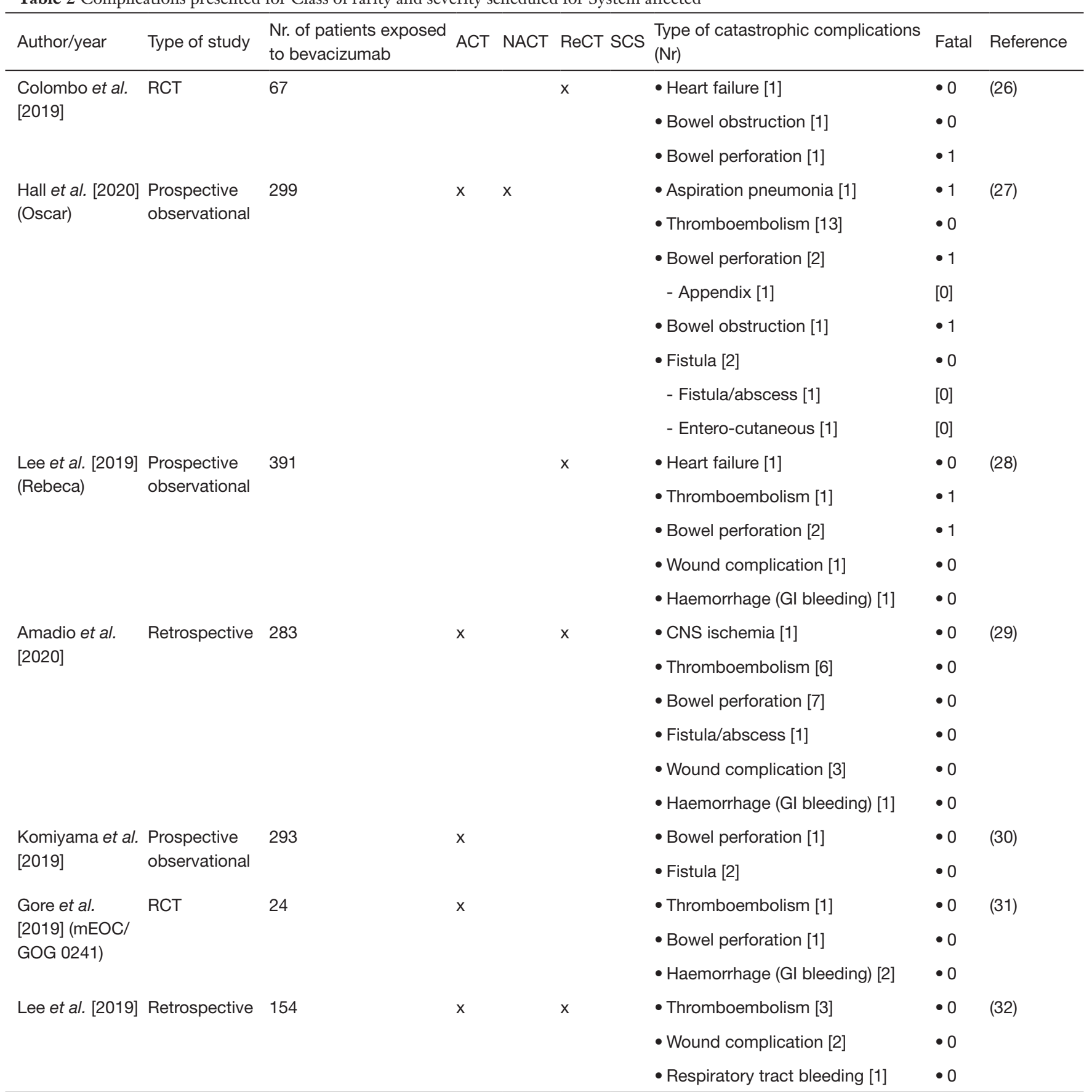

Table 2 (continued) 
Table 2 (continued)

\begin{tabular}{|c|c|c|c|c|c|c|c|c|c|}
\hline Author/year & Type of study & $\begin{array}{l}\text { Nr. of patients exposed } \\
\text { to bevacizumab }\end{array}$ & ACT & NACT & $\mathrm{ReCT}$ & scs & $\begin{array}{l}\text { Type of catastrophic complications } \\
(\mathrm{Nr})\end{array}$ & Fatal & Reference \\
\hline \multirow[t]{7}{*}{$\begin{array}{l}\text { Selle et al. } \\
\text { [2017] (ROSiA) }\end{array}$} & \multirow[t]{7}{*}{$\begin{array}{l}\text { Prospective } \\
\text { observational }\end{array}$} & \multirow[t]{7}{*}{1021} & \multirow[t]{7}{*}{$x$} & \multirow[t]{7}{*}{$x$} & & & $\begin{array}{l}\text { - Posterior leukoencephalopathy } \\
\text { syndrome [1] }\end{array}$ & $\cdot 0$ & \multirow[t]{7}{*}{ (33) } \\
\hline & & & & & & & - Heart failure [2] & $\bullet 1$ & \\
\hline & & & & & & & - Thromboembolism [11] & $\cdot 3$ & \\
\hline & & & & & & & - Venous thr. [7] & [1] & \\
\hline & & & & & & & - Bowel perforation [5] & $\bullet 1$ & \\
\hline & & & & & & & - Fistula/abscess [1] & $\bullet 0$ & \\
\hline & & & & & & & - Haemorrhage [3] & - 1 & \\
\hline \multirow{2}{*}{ Tew et al. [2018] } & \multirow{2}{*}{$\mathrm{RCT}$} & \multirow{2}{*}{150} & & & \multirow{2}{*}{\multicolumn{2}{|c|}{$x$}} & • Bowel perforation [3] & $\bullet 1$ & \multirow{2}{*}{$(35)$} \\
\hline & & & & & & & • Haemorrhage [1] & $\bullet 1$ & \\
\hline \multirow{3}{*}{$\begin{array}{l}\text { Chikazawa et al. } \\
\text { [2018] }\end{array}$} & \multirow{3}{*}{ Retrospective } & \multirow[t]{3}{*}{25} & & & \multirow{3}{*}{\multicolumn{2}{|c|}{$x$}} & - Thromboembolism [1] & $\bullet 0$ & \multirow[t]{3}{*}{$(36)$} \\
\hline & & & & & & & • Bowel perforation [3] & $\bullet 0$ & \\
\hline & & & & & & & - Haemorrhage (GI bleeding) [1] & $\bullet 1$ & \\
\hline $\begin{array}{l}\text { Hiranuma et al. } \\
\text { [2018] }\end{array}$ & Case report & 1 & $x$ & & & & - Aortititis [1] & $\bullet 0$ & (37) \\
\hline $\begin{array}{l}\text { Geltzeiler et al. } \\
{[2017]}\end{array}$ & Case report & 1 & $x$ & & & & - Nasal anterior septal perforation [1] & ]$\bullet 0$ & (38) \\
\hline \multirow{3}{*}{$\begin{array}{l}\text { Dalton et al. } \\
\text { [2017] }\end{array}$} & \multirow{3}{*}{ Retrospective } & \multirow{3}{*}{40} & & & \multirow{3}{*}{\multicolumn{2}{|c|}{$x$}} & - Abscess [1] & $\cdot 0$ & \multirow{3}{*}{$(40)$} \\
\hline & & & & & & & - Acute renal failure [1] & $\cdot 0$ & \\
\hline & & & & & & & - Breast lymphangitis [1] & $\cdot 0$ & \\
\hline \multirow{6}{*}{$\begin{array}{l}\text { Coleman et al. } \\
\text { [2017] (GOG- } \\
\text { 0213) }\end{array}$} & \multirow[t]{6}{*}{$\mathrm{RCT}$} & \multirow[t]{6}{*}{337} & & & \multirow{6}{*}{\multicolumn{2}{|c|}{$x$}} & - CNS haemorrhage [1] & $\cdot 1$ & \multirow[t]{6}{*}{$(18)$} \\
\hline & & & & & & & - Heart failure [1] & $\cdot 0$ & \\
\hline & & & & & & & - Thromboembolism [22] & $\bullet 0$ & \\
\hline & & & & & & & - Arterial thr. [22] & {$[0]$} & \\
\hline & & & & & & & - Bowel perforation [6] & $\bullet 0$ & \\
\hline & & & & & & & - Abscess [2] & $\bullet 2$ & \\
\hline $\begin{array}{l}\text { Martin et al. } \\
{[2016]}\end{array}$ & Retrospective & 60 & & & $x$ & & - Fistula [1] & $\bullet 0$ & $(41)$ \\
\hline
\end{tabular}

Table 2 (continued) 
Table 2 (continued)

\begin{tabular}{|c|c|c|c|c|c|c|c|c|}
\hline Author/year & Type of study & $\begin{array}{l}\text { Nr. of patients exposed } \\
\text { to bevacizumab }\end{array}$ & ACT & NACT & ReCT SCS & $\begin{array}{l}\text { Type of catastrophic complications } \\
(\mathrm{Nr})\end{array}$ & Fatal & Reference \\
\hline \multirow[t]{3}{*}{$\begin{array}{l}\text { Daniele et al. } \\
\text { [2016] }\end{array}$} & \multirow[t]{3}{*}{$\begin{array}{l}\text { Prospective } \\
\text { Phase iv }\end{array}$} & \multirow[t]{3}{*}{74} & & \multirow{3}{*}{\multicolumn{2}{|c|}{$\mathrm{x}$}} & \multicolumn{2}{|l|}{$\begin{array}{l}\text { - Bowel perforation [1] (anastomotic • } 0 \\
\text { leak) }\end{array}$} & (9) \\
\hline & & & & & & - Bowel obstruction [1] & $\bullet 0$ & \\
\hline & & & & & & - Abscess [1] & $\bullet 0$ & \\
\hline \multirow{3}{*}{$\begin{array}{l}\text { Gouy et al.* } \\
\text { [2016] }\end{array}$} & \multirow{3}{*}{$\begin{array}{l}\text { Prospective } \\
\text { phase I }\end{array}$} & \multirow[t]{3}{*}{20} & \multirow[t]{3}{*}{$x$} & & & - Fistula [2] & $\bullet 0$ & \multirow[t]{3}{*}{$(11)$} \\
\hline & & & & & & $\begin{array}{l}\text { - Eventration complicated by small } \\
\text { bowel fistula [1] }\end{array}$ & I [0] & \\
\hline & & & & & & - Entero-cutaneus [1] & [0] & \\
\hline \multirow{6}{*}{$\begin{array}{l}\text { Selle et al. } \\
\text { [2016] }\end{array}$} & \multirow{6}{*}{ Retrospective } & \multirow{6}{*}{156} & & & \multirow{6}{*}{$x$} & • Thromboembolism [4] & $\bullet 1$ & \multirow{6}{*}{ (43) } \\
\hline & & & & & & - Arterial thr. [1] & {$[1]$} & \\
\hline & & & & & & - Pulmonary hypertension [1] & $\bullet 1$ & \\
\hline & & & & & & - Bowel perforation [1] & $\bullet 1$ & \\
\hline & & & & & & - Fistula [4] & $\bullet 0$ & \\
\hline & & & & & & - Haemorrhage (GI bleeding) [4] & $\bullet 1$ & \\
\hline $\begin{array}{l}\text { Petrillo et al. } \\
\text { [2015] }\end{array}$ & Retrospective & 25 & & \multirow{4}{*}{\multicolumn{2}{|c|}{$x$}} & • Thromboembolism [1] & $\bullet 0$ & $(7)$ \\
\hline \multirow{3}{*}{$\begin{array}{l}\text { Burger et al. } \\
\text { [2014] (GOG- } \\
\text { 0218) }\end{array}$} & \multirow{3}{*}{$\mathrm{RCT}$} & \multirow{3}{*}{1,248} & \multirow{3}{*}{$x$} & & & - Anastomotic leak [2] & {$[0]$} & \multirow{3}{*}{ (44) } \\
\hline & & & & & & - Bowel necrosis [1] & $\cdot 1$ & \\
\hline & & & & & & • Fistula [3] & $\bullet 0$ & \\
\hline
\end{tabular}

Table 2 (continued) 
Table 2 (continued)

\begin{tabular}{|c|c|c|c|c|c|c|c|c|}
\hline Author/year & Type of study & $\begin{array}{l}\text { Nr. of patients exposed } \\
\text { to bevacizumab }\end{array}$ & ACT & NACT & ReCT SCS & $\begin{array}{l}\text { Type of catastrophic complications } \\
(\mathrm{Nr})\end{array}$ & Fatal & Reference \\
\hline \multirow{7}{*}{$\begin{array}{l}\text { Pujade-Lauraine } \\
\text { et al. [2014] } \\
\text { (AURELIA) }\end{array}$} & \multirow{7}{*}{ RCT } & \multirow[t]{7}{*}{179} & & & & $\begin{array}{l}\text { - Reversible posterior } \\
\text { leukoencephalopathy syndrome [1] }\end{array}$ & $\bullet 0$ & \multirow[t]{7}{*}{$(45)$} \\
\hline & & & & & & - Heart failure [1] & - 1 & \\
\hline & & & & & & - Thromboembolism [9] & $\bullet 0$ & \\
\hline & & & & & & - Venous thr. [5] & {$[0]$} & \\
\hline & & & & & & - Bowel perforation [3] & $\bullet 1$ & \\
\hline & & & & & & - Fistula/abscess [2] & - 1 & \\
\hline & & & & & & - Septic Shock [1] & - 1 & \\
\hline $\begin{array}{l}\text { Kountourakis et } \\
\text { al. [2014] }\end{array}$ & Case report & 1 & $x$ & & & - Dysphonia [1] & $\cdot 0$ & $(47)$ \\
\hline $\begin{array}{l}\text { Salani et al. } \\
\text { [2014] }\end{array}$ & $\begin{array}{l}\text { Prospective } \\
\text { phase I }\end{array}$ & 9 & & $x$ & & $\begin{array}{l}\text { - Bowel perforation [1] (anastomotic } \\
\text { leak) }\end{array}$ & $\bullet 0$ & (6) \\
\hline \multirow[t]{3}{*}{$\begin{array}{l}\text { Herzog et al. } \\
\text { [2014] }\end{array}$} & \multirow[t]{3}{*}{$\begin{array}{l}\text { Prospective } \\
\text { observational }\end{array}$} & \multirow[t]{3}{*}{132} & & & & $\begin{array}{l}\text { - Posterior leukoencephalopathy } \\
\text { syndrome [1] }\end{array}$ & $\bullet 0$ & \multirow[t]{3}{*}{$(48)$} \\
\hline & & & & & & • Thromboembolism [3] & $\cdot 0$ & \\
\hline & & & & & & - Bowel perforation [1] & $\bullet 1$ & \\
\hline \multirow{6}{*}{$\begin{array}{l}\text { Tillmanns et } \\
\text { al. }{ }^{\star \star \star}[2013]\end{array}$} & \multirow{6}{*}{$\begin{array}{l}\text { Prospective } \\
\text { phase II }\end{array}$} & \multirow[t]{6}{*}{48} & & & \multirow[t]{6}{*}{$x$} & - Heart failure [1] & $\cdot 0$ & \multirow[t]{6}{*}{$(51)$} \\
\hline & & & & & & • Thromboembolism [2] & $\cdot 0$ & \\
\hline & & & & & & - Pneumonia [1] & $\cdot 0$ & \\
\hline & & & & & & - Bowel perforation [2] & $\cdot 0$ & \\
\hline & & & & & & - Bowel obstruction [5] & $\cdot 0$ & \\
\hline & & & & & & - Acute renal failure [1] & $\cdot 0$ & \\
\hline $\begin{array}{l}\text { Mantia- } \\
\text { Smaldone et al. } \\
{[2013]}\end{array}$ & Case report & 1 & & & $x$ & $\begin{array}{l}\text { - Vertebral artery dissection and } \\
\text { CSN haemorrhage [1] }\end{array}$ & $\bullet 0$ & $(52)$ \\
\hline
\end{tabular}

Table 2 (continued) 
Table 2 (continued)

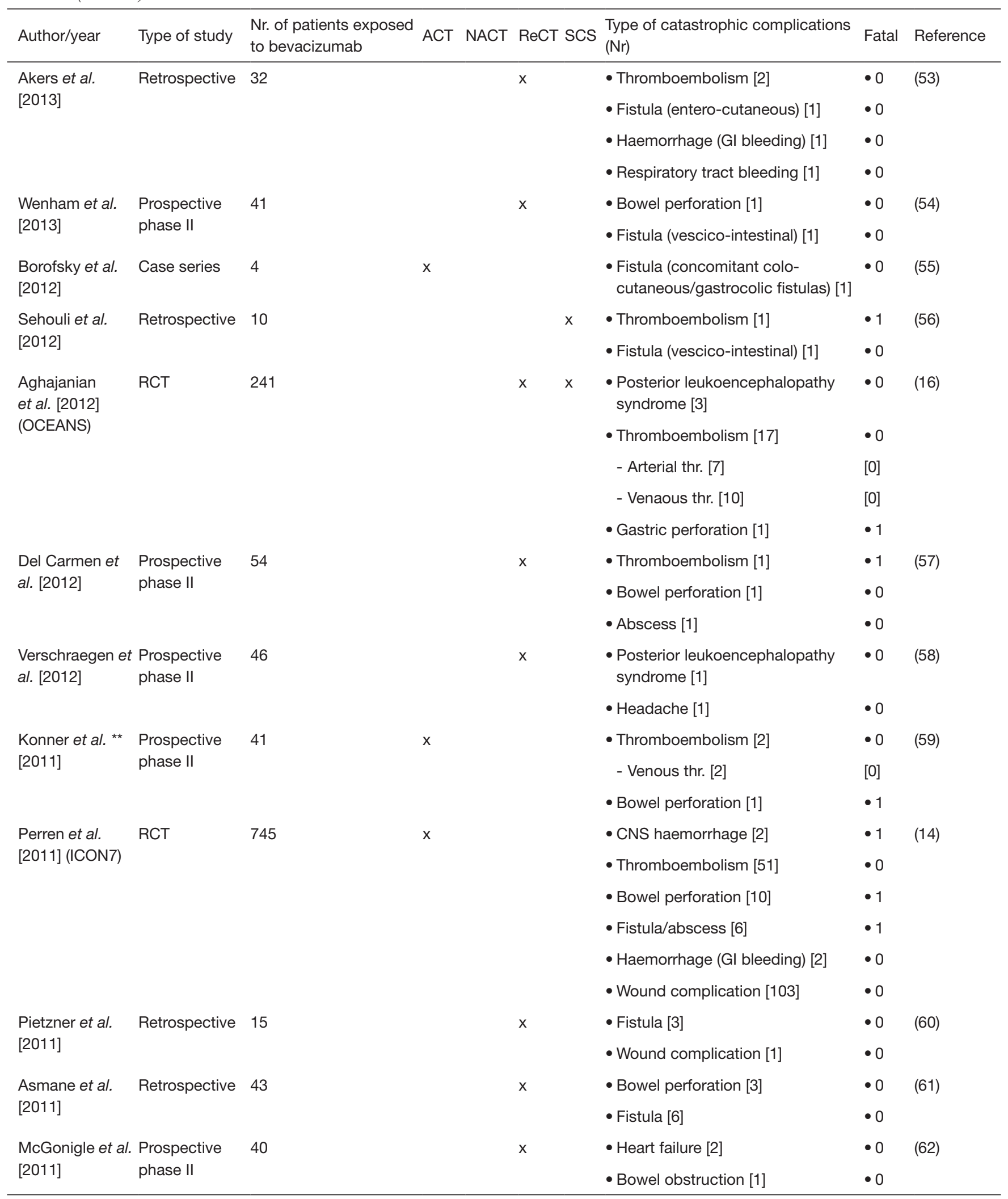

Table 2 (continued) 
Table 2 (continued)

\begin{tabular}{|c|c|c|c|c|c|c|c|c|}
\hline Author/year & Type of study & $\begin{array}{l}\text { Nr. of patients exposed } \\
\text { to bevacizumab }\end{array}$ & ACT & NACT & ReCT SCS & $\begin{array}{l}\text { Type of catastrophic complications } \\
(\mathrm{Nr})\end{array}$ & Fatal & Reference \\
\hline \multirow{3}{*}{$\begin{array}{l}\text { Tanyi et al. } \\
\text { [2011] }\end{array}$} & \multirow[t]{3}{*}{ Retrospective } & \multirow[t]{3}{*}{82} & & & \multirow[t]{3}{*}{$x$} & • Thromboembolism [12] & $\bullet 0$ & (63) \\
\hline & & & & & & - Bowel perforation [6] & $\bullet 1$ & \\
\hline & & & & & & $\begin{array}{l}\text { - Double bowel perforation/ } \\
\text { perforation not found [1] }\end{array}$ & $\bullet[1]$ & \\
\hline \multirow{3}{*}{$\begin{array}{l}\text { Sánchez-Muñoz } \\
\text { et al. [2010] }\end{array}$} & \multirow{3}{*}{ Retrospective } & \multirow[t]{3}{*}{38} & & & \multirow[t]{3}{*}{$x$} & • Thromboembolism [1] & $\bullet 0$ & (64) \\
\hline & & & & & & - Arterial thr. [1] & [0] & \\
\hline & & & & & & - Fistula [1] & $\bullet 0$ & \\
\hline $\begin{array}{l}\text { Richardson et } \\
\text { al. [2010] }\end{array}$ & Retrospective & 35 & & & $x$ & • Bowel perforation [2] & $\bullet 0$ & $(65)$ \\
\hline \multirow{2}{*}{ Diaz et al. [2010] } & \multirow{2}{*}{ Retrospective } & \multirow{2}{*}{160} & & & \multirow{2}{*}{$x$} & - Appendix [1] & [0] & \multirow{2}{*}{$(66)$} \\
\hline & & & & & & - Not found [4] & [4] & \\
\hline $\begin{array}{l}\text { Cheng et al. } \\
\text { [2009] }\end{array}$ & Retrospective & 62 & & & $x$ & • Bowel perforation [2] & $\bullet 0$ & $(67)$ \\
\hline Hurt et al. [2009] & Retrospective & 51 & & & $x$ & - Bowel perforation [3] & $\bullet 0$ & $(68)$ \\
\hline $\begin{array}{l}\text { Sfakianos et al. } \\
\text { [2009] }\end{array}$ & Retrospective & 68 & & & $x$ & - Bowel perforation [5] & $\bullet 0$ & (69) \\
\hline $\begin{array}{l}\text { Nimeiri et al. } \\
\text { [2008] }\end{array}$ & $\begin{array}{l}\text { Prospective } \\
\text { phase II }\end{array}$ & 13 & & & $x$ & - Bowel perforation [1] & $\cdot 1$ & $(70)$ \\
\hline \multirow{2}{*}{$\begin{array}{l}\text { Wright et al. } \\
\text { [2007] }\end{array}$} & \multirow[t]{2}{*}{ Retrospective } & \multirow[t]{2}{*}{62} & & & \multirow[t]{2}{*}{$\mathrm{x}$} & - Bowel perforation [4] & $\bullet 0$ & (72) \\
\hline & & & & & & - Chylous ascites [3] & $\bullet 0$ & \\
\hline \multirow{6}{*}{$\begin{array}{l}\text { Cannistra et al. } \\
\text { [2007] }\end{array}$} & \multirow{6}{*}{$\begin{array}{l}\text { Prospective } \\
\text { phase II }\end{array}$} & \multirow[t]{6}{*}{44} & & & \multirow[t]{6}{*}{$\mathrm{x}$} & - CNS ischemia [1] & $\bullet 1$ & (73) \\
\hline & & & & & & $\begin{array}{l}\text { - Convulsion and endocranic } \\
\text { hypertension [1] }\end{array}$ & $\bullet 1$ & \\
\hline & & & & & & • Thromboembolism [3] & $\bullet 0$ & \\
\hline & & & & & & - Arterial thr. [3] & {$[0]$} & \\
\hline & & & & & & - Bowel perforation [5] & $\bullet 1$ & \\
\hline & & & & & & - Fistula/abscess [1] & $\bullet 1$ & \\
\hline Total & 56 & 7,096 & 16 & 5 & 36 & 591 & 57 & \\
\hline
\end{tabular}

*, dose-finding trial of hyperthermic intraperitoneal cisplatin for IDS followed by maintenance bevacizumab; **, intravenous carboplatin+bevacizumab and intra-abdominal paclitaxel; ${ }^{\star \star \star}$, bevacizumab with albumin-bound paclitaxel. ACT, adjuvant chemotherapy; NACT, neoadjuvant chemotherapy; ReCT, salvage chemotherapy (recurrences); SCS, secondary cytoreductive surgery associated to bevacizumab infusion; RCT, randomized controlled trial. 
Table 3 Case series of the extreme complications associated to bevacizumab administration noticed at our institutions

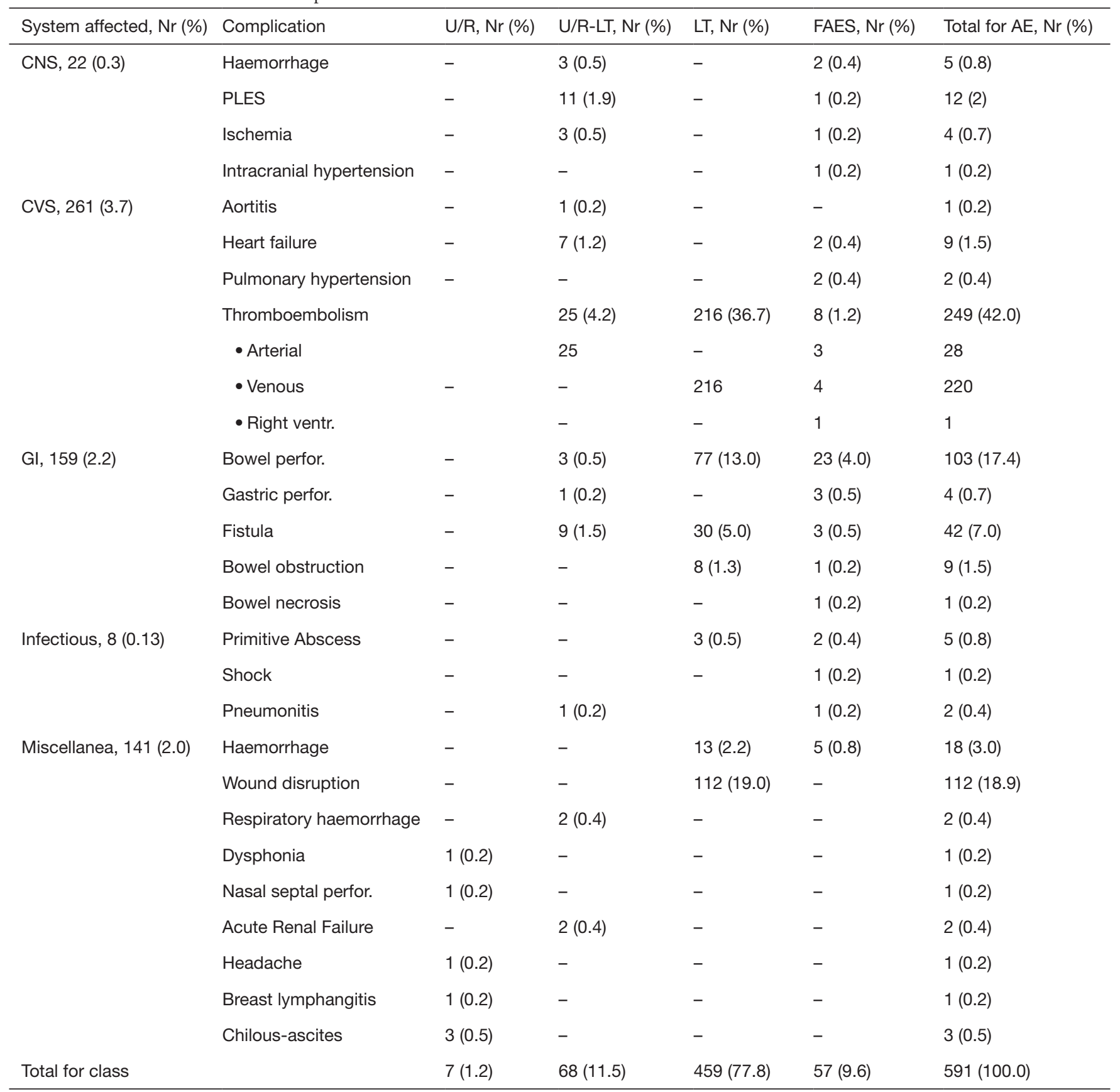

AE, adverse event; U/R, uncommon/rare; U/R-LT, U/R and life-threatening; LT, life-threatening; FAES, fatal; CNS, Central Nervous System; CVS, Cardio-Vascular System; GI, Gastro-intestinal System. 
Events reported included 1 case $(0.01 \%)$ of aortitis, 9 cases $(0.13 \%)$ of heart failure, 2 cases $(0.02)$ of pulmonary hypertension, and 249 cases $(3.5 \%)$ of thromboembolism [including 1 case $(0.01 \%)$ with right ventricular thrombus]. Those AEs accounted for $0.4 \%, 3.4 \%, 0.8 \%$, and $95 \%$ of the CVS morbidity, respectively. In particular, arterial thromboses were seen in 28 cases (11\%).

Overall, GI complications numbered 159 (2.2\%), representing $26.8 \%$ of the global morbidity. Bowel perforations were seen in 103 cases $(1.4 \%)$, gastric perforations in 4 cases $(0.05 \%)$, fistulae in 42 cases $(0.6 \%)$, bowel obstruction in 9 cases $(0.1 \%)$, and bowel necrosis in 1 case $(0.01 \%)$, representing the $62.5 \%, 2.6 \%, 27 \%, 6 \%$, and $0.6 \%$ of the GI morbidity, respectively.

Primitive infectious complications were observed in 8 cases $(0.13 \%)$, representing $1.4 \%$ of the global morbidity. One case $(0.01 \%)$ of septic shock, 5 cases $(0.07 \%)$ with abscesses and 2 cases $(0.02 \%)$ of pneumonitis were recorded, representing $12.5 \%, 62.5 \%$ and $25 \%$ of the infectious morbidity, respectively.

Miscellaneous complications numbered 141 cases (2\%) representing $23.9 \%$ of the global morbidity. Of significance, hemorrhages were seen in 18 cases $(0.25 \%)$, representing $3 \%$ of the global morbidity, while wound complications numbered 112 cases (1.6\%), representing $18.9 \%$ of the global morbidity.

Additional AEs noted were 2 cases $(0.02 \%)$ of pulmonary hemorrhage, 1 case $(0.01 \%)$ of reversible dysphonia, 1 case $(0.01 \%)$ of anterior nasal septal perforation, 2 cases $(0.02 \%)$ of acute renal failure (ARF), 1 case $(0.01 \%)$ of G4 headache, 1 case $(0.01 \%)$ of breast lymphangitis and 3 cases $(0.04 \%)$ of Chilous ascites. These AEs represented 18\%, 9\%, 9\%, $18 \%, 9 \%, 9 \%, 8 \%$ and $27 \%$ of the miscellaneous morbidity, respectively.

According to the frequency and severity classification, among the AEs, there were 7 U/R (0.1\%), 75 U/R-LT $(0.96 \%)$, and 459 LT $(6.4 \%)$, as well as 58 FAEs $(0.8 \%)$, representing $1.2 \%, 11.5 \%, 77.8 \%$ and $9.6 \%$ of the overall morbidity, respectively (Table 3).

Among U/R AEs, 1 case of nasal anterior septal perforation, 1 case of reversible dysphonia, 1 case of severe headache (G4), 1 case of breast lymphangitis and 3 cases of Chilous-ascites were reported.

Regarding U/R-LT AEs there were 2 cases of CNS hemorrhage, 1 rare case of vertebral artery dissection with subsequent CSN hemorrhage, 11 cases of PLES, 3 cases of ischemia, 1 case of aortitis, 7 cases of heart failure and 25 cases of arterial thromboembolism. GI related issues included 1 rare case of double consecutive bowel perforation at three months, 2 cases of appendix perforation, 1 case of gastric perforation, 9 cases of varying and complex fistulae, including 1 case of eventration complicated by a small bowel fistula, 3 entero-cutaneous fistulae, 1 gastro-pleural fistula, 2 vesico-intestinal fistulae and 1 case of concomitant colo-cutaneous/gastro-colic fistula. Regarding infections, an $\mathrm{AE}$ was seen in 1 case with pneumonia. Miscellaneous complications were observed in 2 cases consisting of respiratory tract hemorrhage, as well as 2 cases of ARF.

LT AEs included 216 cases of thromboembolism, 73 bowel perforations associated with 4 anastomotic leeks, 30 cases of fistulae, of which 12 were complicated by abscess formation, 8 cases of bowel obstruction, 3 primary abscesses, 13 hemorrhagic events, and, in all cases [112], of severe wound-healing complications.

Regarding FAEs, of the CNS complications there were 2 cases of intracranial hemorrhage, 1 case of PLES, 1 case of cerebral ischemia and 1 case of seizures due to intracranial hypertension. Cardiovascular complications included 2 cases of heart failure, 2 cases of pulmonary hypertension, 7 cases of thromboembolism (of which 3 cases were of arterial origin and 1 case was of rare right ventricle thrombus). GI complications included 23 bowel perforations, in which the perforation could not be identified in 5 cases, and 1 case of a double perforation. In addition, 3 cases of gastric perforation, 3 cases of fistulae complicated by abscess formation, 1 case of bowel obstruction, and 1 case of bowel necrosis were observed. Regarding infectious issues, there were 2 cases of abdominal abscesses and 1 case of septic shock of unknown origin. There were also 1 case of aspiration pneumonia and 5 cases of hemorrhagic events.

The specific mortality-rate was calculated for each AE. Intracranial hypertension resulted in $100 \%$ of mortality, while intracranial hemorrhage, ischemia and PLES were responsible for $40 \%, 25 \%$ and $8 \%$ of mortality, respectively. Among CVS complications, right ventricle thrombus and pulmonary hypertension resulted in $100 \%$ mortality, while heart failure had a mortality of $22 \%$. Arterial thrombosis resulted in $10.7 \%$ mortality, while thromboembolism, overall, resulted in a mortality-rate of $2.8 \%$. Gastric and bowel perforations had a mortality-rate of $75 \%$ and $20 \%$, respectively. The mortality seen in cases in which the site of bowel perforation could not be identified rose to $100 \%$. Bowel obstruction and fistulae complicated by abscess formation demonstrated a mortality-rate of $11 \%$ and $7 \%$, respectively, while bowel necrosis was $100 \%$ fatal. 
Primitive abscesses resulted in a mortality-rate of $40 \%$ and pneumonitis, $50 \%$. Lastly, hemorrhages were associated with a mortality-rate of $28 \%$.

Table 4 shows the suggested AEs's treatment, reported by system affected.

\section{Discussion}

Much scientific evidence has confirmed that bevacizumab offers advantages in terms of PFS in high-risk and recurrent OC, and presents an acceptable safety profile. Additionally, other studies have demonstrated improved overall survival in this subset of patient $(1,14,16,45)$.

Recently, bevacizumab was confirmed to be safe when employed with cytoreductive surgery although with a recommendation to maintain a time interval of 40 days between surgery and bevacizumab administration $(3,4,16,18)$.

Nevertheless, compared to the benefits, AEs are more common in patients receiving bevacizumab than in those receiving standard chemotherapy regimens $(14-17,18)$.

The overall toxicity rate (all grades) of bevacizumabcontaining chemotherapy in the most representative studies in literature ranged from $61 \%$ (ICON7) to $100 \%$ (GOG218, ROSiA, OSCAR) in front-line, and from $57 \%$ to $100 \%$ at recurrence (AURELIA, GOG-213-OCEAN) $(14-16,18,27,28,33)$. Given these findings, bevacizumab has been recognized as a risk factor for peculiar drug-related AEs, such as hypertension, proteinuria, bleeding, disruption of wound healing, GI perforations, and arterial and venous thrombosis events (1).

Although such trials provide clear evidence of efficacy, randomized phase-III trials typically have strict eligibility criteria, and the selected populations often are not fully representative of patients presenting in routine oncology practice. It is important to assess whether toxicity outcomes observed in rigorously conducted randomized phase-III trials are duplicated in common practice, where patients typically have more co-morbidities (27).

The current literature is particularly rich with data concerning drug-specific toxicity (such as causing hypertension and proteinuria, or hematological, GI and thromboembolic events), but much less is known about the real incidence and severity of rarer and often catastrophic complications. Data about common AEs are rarely categorized by type, and overall toxicity rates always include grade 3 events. Rates of rare and severe toxicity (G4-G5) remain obscure $(14,16-18,44)$.
The overall rate of extreme complication observed in this review was $8.3 \%$, and the overall-LT AEs (7.4\%) represented $89 \%$ of all complications.

An authoritative review of the literature based on a total of 10,217 patients presenting with a variety of advanced solid tumors from 16 RCTs, reported that the overall incidence of FAEs with bevacizumab was $2.9 \%$ (2). This finding is not consistent with our results of $0.8 \%$, which may be due to differences of pathology, surgeries and, above all, different types of chemotherapy schedules adopted.

Fifty-one $(89 \%)$ cases out of FAEs, had the same diagnosis of overall-LT events, while $6(11 \%)$ were new specific fatal diagnosis (intracranial hypertension, pulmonary hypertension, thrombosis in the right ventricle, bowel necrosis, septic shock of unknown origin) that presented a mortality-rate of $100 \%$.

Intracranial hemorrhage, gastric perforation, infectious complications and pneumonitis produced a mortalityrate of over the $30 \%$ and represented the most fearful complications. Cases in which the site of a bowel perforation could not be located were fatal $100 \%$ of the time. Hemorrhages achieved a mortality-rate of $27 \%$, while those originating in the GI tract were fatal in $17 \%$.

The overall rate of GI perforation (1.5\%) and the associated mortality-rate (22.4\%) was found to be consistent with previous literature reports, in which such rates ranged between $0-11 \%$ and $20-50 \%(14,18,33,45,66,73)$.

The incidence of fistula was $0.6 \%$ lower than data described previously in the literature, which ranged between $1 \%$ and $15 \%(15,18,27,73)$. The reason for this discrepancy might be explained by the fact that this study considered only serious G4-G5 AEs. This might also explain the differences in the observed rates of thromboembolic events, abscesses, and hemorrhages found in our cohort, which were $3.5 \%, 0,07 \%$ and $0.25 \%$, respectively. These values indeed, are lower than those reported in previous literature, which ranged between $7-9 \%, 1.8-13 \%$, and $2.3-43 \%$, respectively $(9,14-16,18,27,57,73)$.

In our series, patients with U/R-LT complications, and other complications classified in this review as FAEs (such gastric perforation of unknown origin, thrombus in the right ventricle, and GI-hemorrhage due to a rare arterialenteric fistula) survived, thanks to a multidisciplinary effort. Prompt diagnosis and treatment, in spite of the rarity and severity of such complications, can often avoid a fatal outcome.

Based on our experience and the data provided by this review of the literature, it is possible to affirm that clinicians 
Table 4 Recommendations of treatment for the extreme complications associated to bevacizumab administration

\begin{tabular}{|c|c|c|}
\hline System affected & Complication & Recommendations \\
\hline \multirow[t]{8}{*}{ CNS } & Haemorrhage & Prompt evaluation in stroke unit \\
\hline & & Assess the patient's airway, breathing capability, blood pressure and signs of increased ICP \\
\hline & & Permanently discontinue bevacizumab \\
\hline & & Rapid withdrawal of the trigger appears to hasten recovery and avoid complications \\
\hline & & Antiepileptic drugs should be used to treat seizures \\
\hline & & Permanently discontinue bevacizumab \\
\hline & Ischemia & Stroke identification and activation of the stroke unit are the crucial steps \\
\hline & & Permanently discontinue bevacizumab \\
\hline \multirow[t]{9}{*}{ CVS } & Aortitis & $\begin{array}{l}\text { Given the rarity of the event and the heterogeneity of the possible causes (infectious, autoimmune, } \\
\text { idiopathic), the patient should be treated by a multidisciplinary team (composed of gynecologist } \\
\text { oncologist, rheumatologist, cardiovascular medical and surgical specialists) }\end{array}$ \\
\hline & & Consider discontinue bevacizumab \\
\hline & Heart failure & Specialist cardiological evaluation \\
\hline & & Consider discontinue bevacizumab \\
\hline & $\begin{array}{l}\text { Pulmonary } \\
\text { hypertension }\end{array}$ & $\begin{array}{l}\text { If arterial pulmonary blood clots can be identified, anticoagulant therapy, together with drug removal, } \\
\text { should be suggested }\end{array}$ \\
\hline & Venous TE & Prompt start of anticoagulant therapy (LMWH) and discontinuation of bevacizumab \\
\hline & & Consider permanent discontinuation of bevacizumab for complicated venous TE \\
\hline & Right ventricle TE & Prompt start of therapeutic anticoagulation $(\mathrm{LMWH})$ and admission to ICU \\
\hline & & Permanently discontinue bevacizumab \\
\hline \multirow[t]{5}{*}{$\mathrm{Gl}$} & Bowel perforation & Bowel rest and prompt evaluation with water-soluble contrast imaging \\
\hline & Gastric perforation & Based on the patient's clinical condition, surgical correction should be considered \\
\hline & Fistula & Permanently discontinue bevacizumab \\
\hline & Bowel obstruction & \\
\hline & Bowel necrosis & \\
\hline \multirow[t]{4}{*}{ Infectious } & Primitive abscess & Systemic antibiotics \pm drainage (open or percutaneous) \\
\hline & & Consider discontinuation of bevacizumab \\
\hline & Shock & Systemic antibiotics and admission to ICU \\
\hline & & Permanently discontinue bevacizumab \\
\hline
\end{tabular}

Table 4 (continued) 
Table 4 (continued)

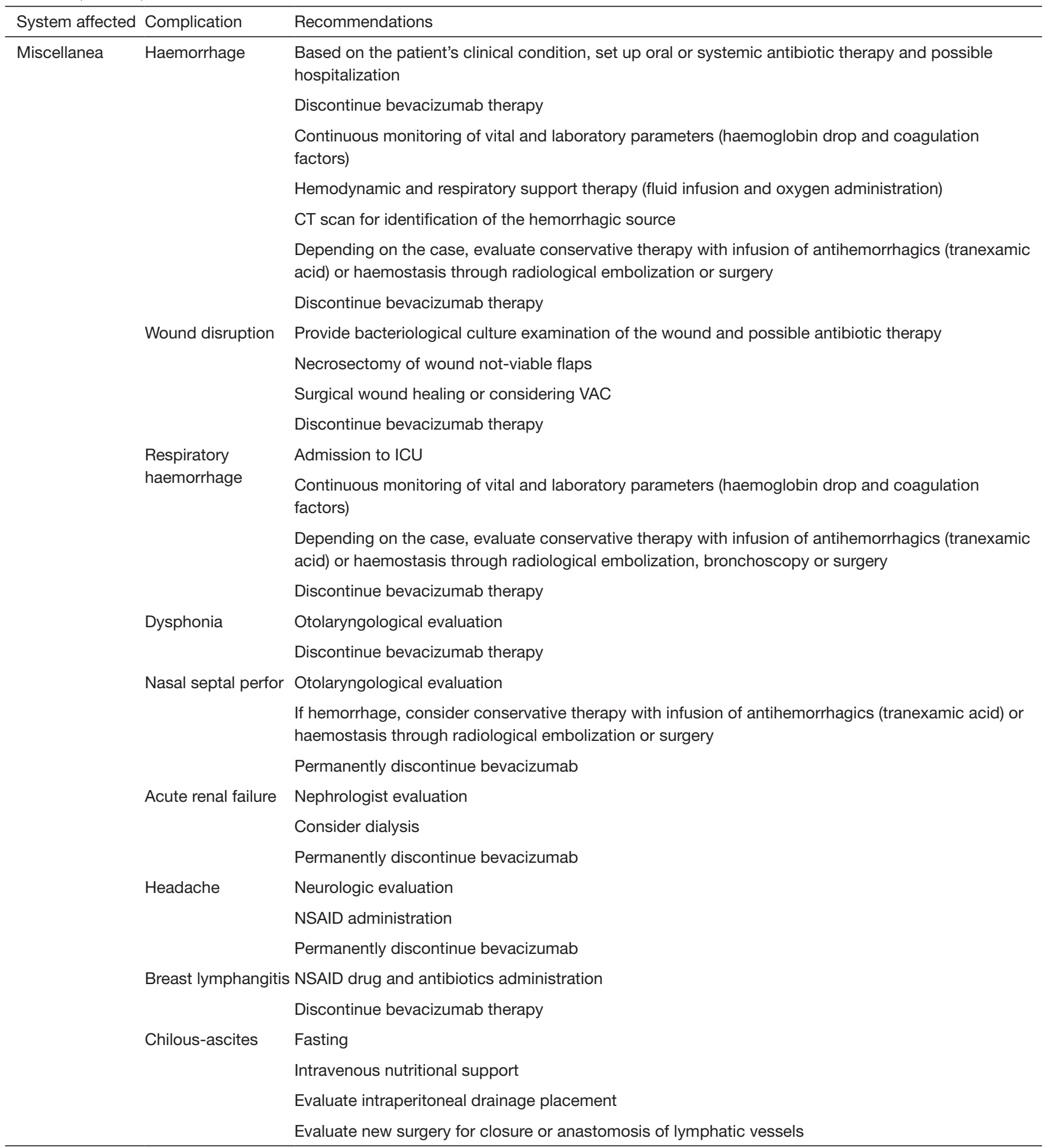

CNS, Central Nervous System; ICP, Intra-Cranial Pressure; PLES, Posterior Leuko-Encephalopathy Syndrome; CVS, Cardio-Vascular System; TE, Thromboembolism; LMWH, Low Molecular Weight Heparin; ICU, Intensive Care Unit; GI, Gastro-intestinal System; VAC, Vacuum Assisted Closure therapy; NSAID, Non-Steroidal Anti-Inflammatory Drug. 
should be able to avoid that $89 \%$ of FAEs which have the same diagnosis as LT cases, have an inauspicious outcome, within the limits in which there is a margin of treatment. In particular, for example it would always be desirable to try finding intestinal perforation, intervening to suture the perforations of the stomach and to perform a toilet/drainage of the abdominal abscesses. A prompt treatment of thromboembolic phenomena with heparin preparations is desirable not only for the most common cases of peripheral thrombosis, but also for the rare cases of intracardiac ventricular thrombi, which should be diagnosed as soon as possible.

The pathophysiology underlying the toxicity associated with bevacizumab are still under study, but it is theroizable on its mechanism of action.

Bevacizumab bind and inactivate VEGF, thereby inhibiting endothelial, and possibly tumor, cell activation and proliferation. Because VEGF also plays an important role in normal physiologic processes, such as stabilization of damaged endothelia, and wound healing-VEGF inhibition carries a unique toxicity profile that involves normal tissues, tumor tissues, and the interface of them (74).

Some AEs, such as bowel perforation and pulmonary hemorrhage seems to be disease site-dependent. Others, such as mucosal bleeding, hypertension, and proteinuria, result to be non-specific and depends on the role of VEGF in stabilization of malignant and nonmalignant blood flow (74).

In particular, as far as CNS toxicity is concerned, it has been postulated that stroke, hemorragies and PLESS are related to the alteration inducted by bevacizumab in the stability of endothelial and the alteration of nitric oxyde production, with the loss of cerebral vascular autoregulation, disruption of the cerebral tissue/capillary interface (bloodbrain barrier), and vasogenic edema (74).

CVS complications appear to share the same pathophysiological mechanisms as CNS.

In particular, arterial and venous thromboembolism and hemorrhage are due to an indirect mechanism of VEGF inhibition in repering damaged endothelial secondary to cardiovascular disease and other microangiopathies. This results in exposed subendothelial tissues that initiate the clotting cascade and subsequent clot formation (74).

Regarding GI complications, the mechanism by which bevacizumab contributes to perforations remains elusive, but it is most likely related to the anti-VEGF effects on bowel perfusion and/or tumor regression, the impaired healing of pathologic or surgical bowel injury, and mesenteric thrombosis and/or vasoconstriction (74).

The disruption of wound healing, including delay, dehiscence, fistula, and abscess are also related with bevacizumab effect on tissues blood perfusion (74).

As suggested by the evidence in the literature (74), the treatment of the various extreme complications associated with bevacizumab must be assessed on a case-by-case basis, considering the features of presentation and patient characteristics (Table 4).

To our knowledge, there is no review in the literature that focuses its results on the rarest and most severe AEs from bevacizumab in the treatment of OC.

The strengths of this study include the originality of the objective, the large number of articles considered, and the substantial population analyzed.

Weaknesses of this study include the heterogeneity of these studies, as well as the population considered. Specifically, phase-I studies were included in the present review, in which the administration of bevacizumab was associated with other drugs under investigation for toxicity (doses and manner of administration). Moreover, the analysed population is compost by patients undergone chemotherapy containing bevacizumab with adjuvant and neoadjuvant purposes, by hardly pre-treated metastatic patients, or even by women subjected to SCS. Furthermore, the doses of bevacizumab and the number of administration cycles at which complications occurred were not reported.

\section{Conclusions}

Extreme complications related to the use of bevacizumab are often unexpected and can prove difficult to diagnose due to their rarity and acuteness of occurrence. The immediate recognition and management of such rare life-threatening complications in a third referral center can improve survival of these patients.

Further studies are needed to better define the incidence and outcomes of extreme AEs in "real-life" population $(28,29)$.

\section{Acknowledgments}

The authors thank Richard H. Renston, $\mathrm{MD}, \mathrm{PhD}$ for his important contribution in revising the form and the English language of this article.

Funding: None.

\section{Footnote}

Reporting Checklist: The authors have completed the AME 
CASE SERIES reporting checklist. Available at http:// dx.doi.org/10.21037/atm-20-4448

Conflicts of Interest: All authors have completed the ICMJE uniform disclosure form (available at http://dx.doi. org/10.21037/atm-20-4448). LCT serves as an unpaid editorial board member of Annals of Translational Medicine from Mar 2020 to Feb 2022. The other authors have no conflicts of interest to declare.

Ethical Statement: The authors are accountable for all aspects of the work in ensuring that questions related to the accuracy or integrity of any part of the work are appropriately investigated and resolved. This study was conducted in accordance with the Declaration of Helsinki (as revised in 2013) and study it was reviewed and approved by the intramural Integrated Research Ethics Board (approval number DIPUSVSP-26-05-2081). Written informed consent was obtained from the patient for publication of this study and any accompanying images.

Open Access Statement: This is an Open Access article distributed in accordance with the Creative Commons Attribution-NonCommercial-NoDerivs 4.0 International License (CC BY-NC-ND 4.0), which permits the noncommercial replication and distribution of the article with the strict proviso that no changes or edits are made and the original work is properly cited (including links to both the formal publication through the relevant DOI and the license). See: https://creativecommons.org/licenses/by-nc-nd/4.0/.

\section{References}

1. Wu YS, Shui L, Shen D, et al. Bevacizumab combined with chemotherapy for ovarian cancer: an updated systematic review and meta-analysis of randomized controlled trials. Oncotarget 2017;8:10703-13.

2. Ranpura V, Hapani S, Wu S. Treatment-related mortality with bevacizumab in cancer patients: a meta-analysis. JAMA 2011;305:487-94.

3. Eveno C, Passot G, Goéré D, et al. Bevacizumab doubles the early postoperative complication rate after cytoreductive surgery with hyperthermic intraperitoneal chemotherapy (HIPEC) for peritoneal carcinomatosis of colorectal origin. Ann Surg Oncol 2014;21:1792-800.

4. Petrillo M, Nero C, Carbone V, et al. Systematic Review of Cytoreductive Surgery and Bevacizumab-Containing Chemotherapy in Advanced Ovarian Cancer: Focus on
Safety. Ann Surg Oncol 2018;25:247-54.

5. Chéreau E, Lambaudie E, Houvenaeghel G. Morbidity of surgery after neoadjuvant chemotherapy including bevacizumab for advanced ovarian cancer. Int J Gynecol Cancer 2013;23:1326-30.

6. Salani R, O'Malley DM, Copeland LJ, et al. Feasibility of interval cytoreduction following neoadjuvant chemotherapy with carboplatin, weekly paclitaxel, and bevacizumab for advanced ovarian cancer--a phase 1 study. Int J Gynecol Cancer 2014;24:682-6.

7. Petrillo M, Paris I, Vizzielli G, et al. Neoadjuvant Chemotherapy Followed by Maintenance Therapy With or Without Bevacizumab in Unresectable High-Grade Serous Ovarian Cancer: A Case-Control Study. Ann Surg Oncol 2015;22 Suppl 3:S952-8.

8. Rouzier R, Gouy S, Selle F, et al. Efficacy and safety of bevacizumab-containing neoadjuvant therapy followed by interval debulking surgery in advanced ovarian cancer: Results from the ANTHALYA trial. Eur J Cancer 2017;70:133-42.

9. Daniele G, Lorusso D, Scambia G, et al. Feasibility and outcome of interval debulking surgery (IDS) after carboplatin-paclitaxel-bevacizumab (CPB): A subgroup analysis of the MITO-16A-MaNGO OV2A phase 4 trial. Gynecol Oncol 2017;144:256-9.

10. Duska LR, Java JJ, Cohn DE, et al. Risk factors for readmission in patients with ovarian, fallopian tube, and primary peritoneal carcinoma who are receiving frontline chemotherapy on a clinical trial (GOG 218): an NRG oncology/gynecologic oncology group study (ADS-1236). Gynecol Oncol 2015;139:221-7.

11. Gouy S, Ferron G, Glehen O, et al. Results of a multicenter phase I dose-finding trial of hyperthermic intraperitoneal cisplatin after neoadjuvant chemotherapy and complete cytoreductive surgery and followed by maintenance bevacizumab in initially unresectable ovarian cancer. Gynecol Oncol 2016;142:237-42.

12. Coleman RL, Spirtos NM, Enserro D, et al. Secondary Surgical Cytoreduction for Recurrent Ovarian Cancer. N Engl J Med 2019;381:1929-39.

13. Gallotta V, Conte C, Giudice MT, et al. Secondary Laparoscopic Cytoreduction in Recurrent Ovarian Cancer: A Large, Single-Institution Experience. J Minim Invasive Gynecol 2018;25:644-50.

14. Perren TJ, Swart AM, Pfisterer J, et al. A phase 3 trial of bevacizumab in ovarian cancer. $\mathrm{N}$ Engl J Med 2011;365:2484-96.

15. Burger RA, Brady MF, Bookman MA, et al. Incorporation 
of bevacizumab in the primary treatment of ovarian cancer. N Engl J Med 2011;365:2473-83.

16. Aghajanian C, Blank SV, Goff BA, et al. OCEANS: a randomized, double-blind, placebo-controlled phase III trial of chemotherapy with or without bevacizumab in patients with platinum-sensitive recurrent epithelial ovarian, primary peritoneal, or fallopian tube cancer. J Clin Oncol 2012;30:2039-45.

17. Poveda AM, Selle F, Hilpert F, et al. Bevacizumab Combined With Weekly Paclitaxel, Pegylated Liposomal Doxorubicin, or Topotecan in Platinum-Resistant Recurrent Ovarian Cancer: Analysis by Chemotherapy Cohort of the Randomized Phase III AURELIA Trial. J Clin Oncol 2015;33:3836-8.

18. Coleman RL, Brady MF, Herzog TJ, et al. Bevacizumab and paclitaxel-carboplatin chemotherapy and secondary cytoreduction in recurrent, platinum-sensitive ovarian cancer (NRG Oncology/Gynecologic Oncology Group study GOG-0213): a multicentre, open-label, randomised, phase 3 trial. Lancet Oncol 2017;18:779-91.

19. Fleming ND, Coleman RL, Tung C, et al. Phase II trial of bevacizumab with dose-dense paclitaxel as firstline treatment in patients with advanced ovarian cancer. Gynecol Oncol 2017;147:41-6.

20. Boussios S, Karihtala P, Moschetta M, et al. Combined Strategies with Poly (ADP-Ribose) Polymerase (PARP) Inhibitors for the Treatment of Ovarian Cancer: A Literature Review. Diagnostics (Basel) 2019;9:87.

21. Common Terminology Criteria for Adverse Events v3.0 2006.

22. CIOMS. Monitoring and assessment of adverse drug effects. 1985.

23. Liberati A, Altman DG, Tetzlaff J, et al. The PRISMA statement for reporting systematic reviews and metaanalyses of studies that evaluate healthcare interventions: explanation and elaboration. BMJ 2009;339:b2700.

24. Cappuccio S, Marinucci B, Bove V, et al. Rare Case of Endoscopic Treatment for Bevacizumab-Related Gastric Perforation in a Patient with Ovarian Cancer. Chemotherapy 2020;65:54-7.

25. Cosentino F, Turco LC, Fagotti A, et al. Arterial-enteric fistula after pelvic lymphadenectomy in secondary cytoreductive surgery for recurrent ovarian cancer. J Obstet Gynaecol 2019;39:1049-56.

26. Colombo N, Zaccarelli E, Baldoni A, et al. Multicenter, randomised, open-label, non-comparative phase 2 trial on the efficacy and safety of the combination of bevacizumab and trabectedin with or without carboplatin in women with partially platinum-sensitive recurrent ovarian cancer. Br J Cancer 2019;121:744-50.

27. Hall M, Bertelli G, Li L, et al. Role of front-line bevacizumab in advanced ovarian cancer: the OSCAR study. Int J Gynecol Cancer 2020;30:213-20.

28. Lee JY, Park JY, Park SY, et al. Real-world effectiveness of bevacizumab based on AURELIA in platinumresistant recurrent ovarian cancer (REBECA): A Korean Gynecologic Oncology Group study (KGOG 3041). Gynecol Oncol 2019;152:61-7.

29. Amadio G, Marchetti C, Villani ER, et al. ToleRability of BevacizUmab in elderly Ovarian cancer patients (TURBO study): a case-control study of a real-life experience. J Gynecol Oncol 2020;31:e6.

30. Komiyama S, Kato K, Inokuchi Y, et al. Bevacizumab combined with platinum-taxane chemotherapy as first-line treatment for advanced ovarian cancer: a prospective observational study of safety and efficacy in Japanese patients (JGOG3022 trial). Int J Clin Oncol 2019;24:103-14.

31. Gore M, Hackshaw A, Brady WE, et al. An international, phase III randomized trial in patients with mucinous epithelial ovarian cancer (mEOC/GOG 0241) with longterm follow-up: and experience of conducting a clinical trial in a rare gynecological tumor. Gynecol Oncol 2019;153:541-8.

32. Lee SP, Hsu HC, Tai YJ, et al. Bevacizumab Dose Affects the Severity of Adverse Events in Gynecologic Malignancies. Front Pharmacol 2019;10:426.

33. Selle F, Colombo N, Korach J, et al. Safety and Efficacy of Extended Bevacizumab Therapy in Elderly ( $\geq 70$ Years) Versus Younger Patients Treated for Newly Diagnosed Ovarian Cancer in the International ROSiA Study. Int J Gynecol Cancer 2018;28:729-37.

34. Nonaka M, Sato S, Osaku D, et al. Recurrent colon perforation after discontinuation of bevacizumab for ovarian cancer. Gynecol Oncol Rep 2018;26:21-3.

35. Tew WP, Sill MW, Walker JL, et al. Randomized phase II trial of bevacizumab plus everolimus versus bevacizumab alone for recurrent or persistent ovarian, fallopian tube or peritoneal carcinoma: An NRG oncology/gynecologic oncology group study. Gynecol Oncol 2018;151:257-63.

36. Chikazawa K, Netsu S, Kuwata T, et al. Bevacizumab improves overall survival in platinum refractory ovarian cancer patients: A retrospective study. Taiwan J Obstet Gynecol 2018;57:819-24.

37. Hiranuma K, Kusunoki S, Fujino K, et al. Drug-induced aortitis in a patient with ovarian cancer treated with 
bevacizumab combination therapy. Taiwan J Obstet Gynecol 2018;57:750-2.

38. Geltzeiler M, Steele TO. Nasal septal perforation secondary to systemic bevacizumab. Am J Otolaryngol 2017;38:354-5.

39. Musa F, Pothuri B, Blank SV, et al. Phase II study of irinotecan in combination with bevacizumab in recurrent ovarian cancer. Gynecol Oncol 2017;144:279-84.

40. Dalton HJ, Fleming ND, Sun CC, et al. Activity of bevacizumab-containing regimens in recurrent low-grade serous ovarian or peritoneal cancer: A single institution experience. Gynecol Oncol 2017;145:37-40.

41. Martin JY, Urban RR, Liao JB, et al. Bevacizumab toxicity in heavily pretreated recurrent epithelial ovarian, fallopian tube, and primary peritoneal cancers. J Gynecol Oncol 2016;27:e47.

42. Miller AH, Monteiro de Oliveira Novaes JA, Brock PA, et al. Posterior reversible encephalopathy syndrome after bevacizumab treatment presenting to the ED as chest pain and headache. Am J Emerg Med 2016;34:1916.e1-2.

43. Selle F, Emile G, Pautier P, et al. Safety of bevacizumab in clinical practice for recurrent ovarian cancer: A retrospective cohort study. Oncol Lett 2016;11:1859-65.

44. Burger RA, Brady MF, Bookman MA, et al. Risk factors for GI adverse events in a phase III randomized trial of bevacizumab in first-line therapy of advanced ovarian cancer: A Gynecologic Oncology Group Study. J Clin Oncol 2014;32:1210-7.

45. Pujade-Lauraine E, Hilpert F, Weber B, et al. Bevacizumab combined with chemotherapy for platinum-resistant recurrent ovarian cancer: The AURELIA open-label randomized phase III trial. J Clin Oncol 2014;32:1302-8.

46. Sawaya R, Radwan W, Hammoud S. Benign reversible encephalopathy syndrome after bevacizumab therapy for metastatic ovarian cancer. Med Oncol 2014;31:831.

47. Kountourakis P, Antoniou G, Papadimitriou K, et al. Voice disorders induced by bevacizumab administration in an ovarian cancer patient: an underestimated and rare toxicity. Hematol Oncol Stem Cell Ther 2014;7:123-4.

48. Herzog TJ, Monk BJ, Rose PG, et al. A phase II trial of oxaliplatin, docetaxel, and bevacizumab as first-line therapy of advanced cancer of the ovary, peritoneum, and fallopian tube. Gynecol Oncol 2014;132:517-25.

49. Wu MD, Wang Y, Ding T, et al. A retrospective clinical study of bevacizumab combined with gemcibabine or paclitaxel in the treatment of recurrent ovarian cancer. Indian J Cancer 2014;51 Suppl 3:e103-5.

50. Dohrmann T, Kutup A, Mahner S, et al. Gastropleural fistula in a patient with recurrent ovarian cancer receiving combination therapy with Carboplatin, gemcitabine, and bevacizumab. J Clin Oncol 2013;31:e208-10.

51. Tillmanns TD, Lowe MP, Walker MS, et al. Phase II clinical trial of bevacizumab with albumin-bound paclitaxel in patients with recurrent, platinum-resistant primary epithelial ovarian or primary peritoneal carcinoma. Gynecol Oncol 2013;128:221-8.

52. Mantia-Smaldone GM, Bagley LJ, Kasner SE, et al. Vertebral artery dissection and cerebral infarction in a patient with recurrent ovarian cancer receiving bevacizumab. Gynecol Oncol Case Rep 2013;5:37-9.

53. Akers SN, Riebandt G, Miller A, et al. Bevacizumab for the treatment of recurrent ovarian cancer: a retrospective cohort study. Eur J Gynaecol Oncol 2013;34:113-9.

54. Wenham RM, Lapolla J, Lin HY, et al. A phase II trial of docetaxel and bevacizumab in recurrent ovarian cancer within 12 months of prior platinum-based chemotherapy. Gynecol Oncol 2013;130:19-24.

55. Borofsky SE, Levine MS, Rubesin SE, et al. Bevacizumabinduced perforation of the gastrointestinal tract: clinical and radiographic findings in 11 patients. Abdom Imaging 2013;38:265-72.

56. Sehouli J, Papanikolaou G, Braicu EI, et al. Feasibility of surgery after systemic treatment with the humanized recombinant antibody bevacizumab in heavily pretreated patients with advanced epithelial ovarian cancer. Ann Surg Oncol 2012;19:1326-33.

57. del Carmen MG, Micha J, Small L, et al. A phase II clinical trial of pegylated liposomal doxorubicin and carboplatin plus bevacizumab in patients with platinumsensitive recurrent ovarian, fallopian tube, or primary peritoneal cancer. Gynecol Oncol 2012;126:369-74.

58. Verschraegen CF, Czok S, Muller CY, et al. Phase II study of bevacizumab with liposomal doxorubicin for patients with platinum- and taxane-resistant ovarian cancer. Ann Oncol 2012;23:3104-10.

59. Konner JA, Grabon DM, Gerst SR, et al. Phase II study of intraperitoneal paclitaxel plus cisplatin and intravenous paclitaxel plus bevacizumab as adjuvant treatment of optimal stage II/III epithelial ovarian cancer. J Clin Oncol 2011;29:4662-8.

60. Pietzner K, Richter R, Chekerov R, et al. Bevacizumab in heavily pre-treated and platinum resistant ovarian cancer: a retrospective study of the North-Eastern German Society of Gynaecologic Oncology (NOGGO) Ovarian Cancer Study Group. Anticancer Res 2011;31:2679-82.

61. Asmane I, Kurtz JE, Bajard A, et al. Bevacizumab plus 
microtubule targeting agents in heavily pre-treated ovarian cancer patients: a retrospective study. Bull Cancer 2011;98:80-9.

62. McGonigle KF, Muntz HG, Vuky J, et al. Combined weekly topotecan and biweekly bevacizumab in women with platinum-resistant ovarian, peritoneal, or fallopian tube cancer: results of a phase 2 study. Cancer 2011;117:3731-40.

63. Tanyi JL, McCann G, Hagemann AR, et al. Clinical predictors of bevacizumab-associated gastrointestinal perforation. Gynecol Oncol 2011;120:464-9.

64. Sánchez-Muñoz A, Mendiola C, Pérez-Ruiz E, et al. Bevacizumab plus low-dose metronomic oral cyclophosphamide in heavily pretreated patients with recurrent ovarian cancer. Oncology 2010;79:98-104.

65. Richardson DL, Backes FJ, Hurt JD, et al. Which factors predict bowel complications in patients with recurrent epithelial ovarian cancer being treated with bevacizumab? Gynecol Oncol 2010;118:47-51.

66. Diaz JP, Tew WP, Zivanovic O, et al. Incidence and management of bevacizumab-associated gastrointestinal perforations in patients with recurrent ovarian carcinoma. Gynecol Oncol 2010;116:335-9.

67. Cheng X, Moroney JW, Levenback CF, et al. What is the benefit of bevacizumab combined with chemotherapy in patients with recurrent ovarian, fallopian tube or primary peritoneal malignancies? J Chemother 2009;21:566-72.

68. Hurt JD, Richardson DL, Seamon LG, et al. Sustained progression-free survival with weekly paclitaxel and

Cite this article as: Turco LC, Ferrandina G, Vargiu V, Cappuccio S, Fagotti A, Sallustio G, Scambia G, Cosentino F. Extreme complications related to bevacizumab use in the treatment of ovarian cancer: a case series from a III level referral centre and review of the literature. Ann Transl Med 2020;8(24):1687. doi: 10.21037/atm-20-4448 bevacizumab in recurrent ovarian cancer. Gynecol Oncol 2009;115:396-400.

69. Sfakianos GP, Numnum TM, Halverson CB, et al. The risk of gastrointestinal perforation and/or fistula in patients with recurrent ovarian cancer receiving bevacizumab compared to standard chemotherapy: a retrospective cohort study. Gynecol Oncol 2009;114:424-6.

70. Nimeiri HS, Oza AM, Morgan RJ, et al. Efficacy and safety of bevacizumab plus erlotinib for patients with recurrent ovarian, primary peritoneal, and fallopian tube cancer: a trial of the Chicago, $\mathrm{PMH}$, and California Phase II Consortia. Gynecol Oncol 2008;110:49-55.

71. Garcia AA, Hirte H, Fleming G, et al. Phase II clinical trial of bevacizumab and low-dose metronomic oral cyclophosphamide in recurrent ovarian cancer: a trial of the California, Chicago, and Princess Margaret Hospital phase II consortia. J Clin Oncol 2008;26:76-82.

72. Wright JD, Secord AA, Numnum TM, et al. A multiinstitutional evaluation of factors predictive of toxicity and efficacy of bevacizumab for recurrent ovarian cancer. Int J Gynecol Cancer 2008;18:400-6.

73. Cannistra SA, Matulonis UA, Penson RT, et al. Phase II study of bevacizumab in patients with platinum-resistant ovarian cancer or peritoneal serous cancer. J Clin Oncol 2007;25:5180-6.

74. Randall LM, Monk BJ. Bevacizumab toxicities and their management in ovarian cancer. Gynecol Oncol 2010;117:497-504 